\title{
توظيف آليات المنطق المضبّب \\ في سبر دلالة أقوال نقاد رجال الحديث النبوي
}

حسن مظفر الرزو

\section{مقدمة"}

بات طرح علم الحديث في عصرنا الراهن مورداً للوقوع في نوعين من المزالق المعرفية، الأول: توهم البعض بأن علم الحديث قد بلغ هايته، وأن ما تبقى لنا لا يزيد

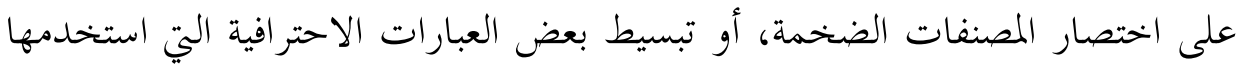

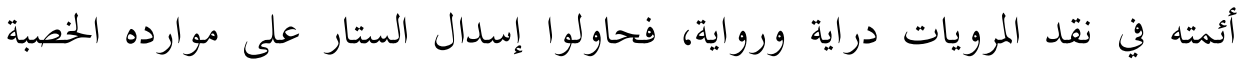

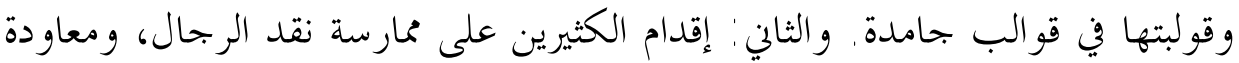
تصحيح المتون، أو تضعيفها دون بلوغهم إلى حقيقة الخطاب السائد بين أئمة الحلديث

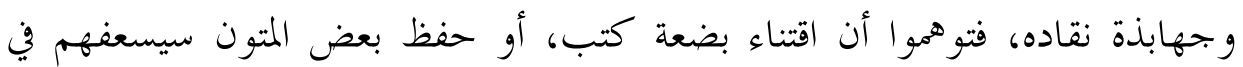

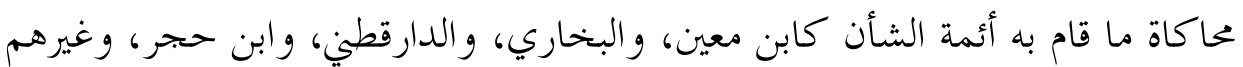
من أئمة هذا العلم.

بيد أن الحقيقة الراسخة في تربة علوم الحميث النبوي الشريف، وبقية العلوم التي

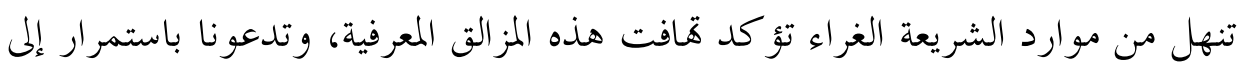

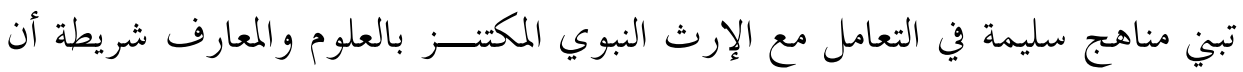

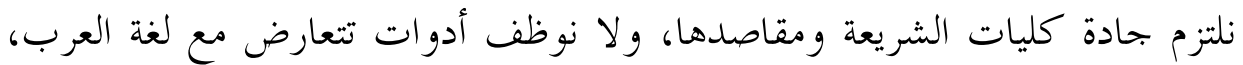
وهج السلف الذي خبر أوجه التوافق بين شريعة الإسلام والبيئة المفاهيمية العربية

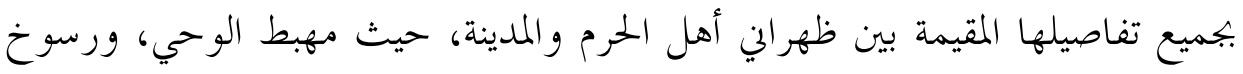

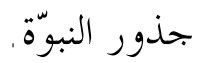


إن السكون يورث الإنسان جموداً في أنماط الفكر التي يستخدمها لفهم الخطاب

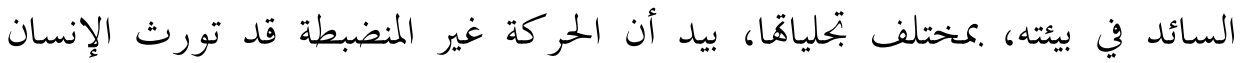
الوقوع في مغبة الخطأ والزلل، أو تبني تفسيرات مستحدثة لخطاب معرفي لا يحتملها.

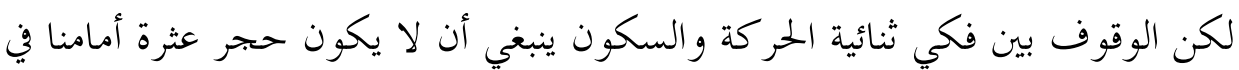

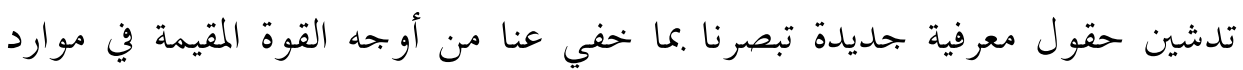

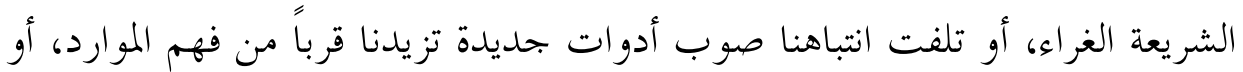
تمنحنا بعضاً من مفاتيح الكنوز المعرفية التي تسهم في دفعنا إلى أمام في عالم الم يعج كفردات التغيير، وإعادة قولبة المفاهيم في كل لحظة.

وون هنا فإن هذا البحث يهدف إلى توظيف المنطق المضبّب في دراسة الأسس

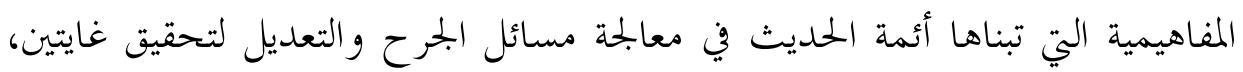
الأولى: سبر ماهية القواعد المستنبطة، والدقة الموضوعية التي كانت تَسمُ أحكامهم النقدية في هذا الميدان، أما الثانية تمهيد الطريق أمام دراسات تستخدم هذه الآلية الآلية المنطقية الذكية لتتناول مسائل شائكة في ميدان علم الحديث مثل الموازنة بين مراتب مئب

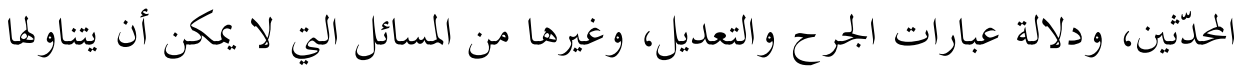

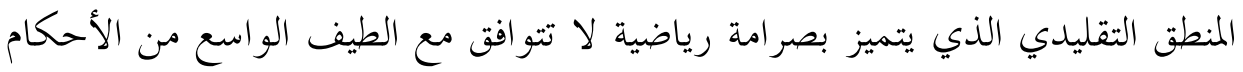

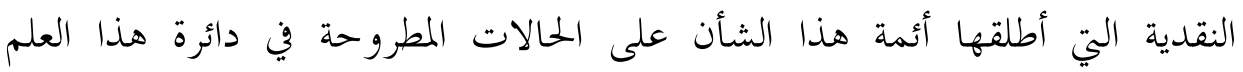

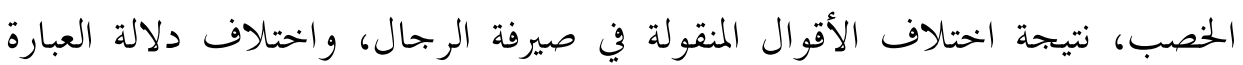
باختلاف العصر الذي قيلت فيه، وغيرها من العوامل المتشابكة التي لم يعد المسلم

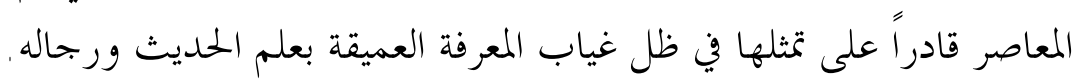

وبتحر الإشارة إلى أنه لم نعثر على تطبيقات مشابهة للمنطق المضبّب في علم الحديث، ونرجو أن تكون المعالجة المعلوماتية التي سنمارسها بواسطة آلياته الجحديدة على مسألة نقد الرجال في علم الحديث النبوي خطوة في إطار حركة شاملة منضبطة،

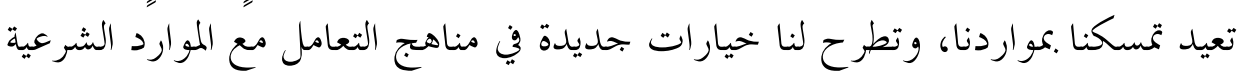
بعيداً عن السكون الذي بات يتبادل موقعه مع الجمود في كثير من الأحيان في بيئنا 


\section{أولاً: المنطق المضبّب: معالجة مفاهيمية}

قد تورث مطالعة عبارة المنطق المضبّب للكثير منا تصور وجود تناقض في دلالة ألفاظ هذا المصطلح. فأرسطو الذي أنشأ اللبنات الأولى للمنطق قد أورثنا قناعات

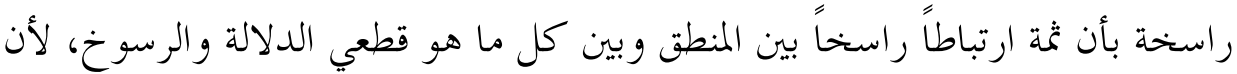

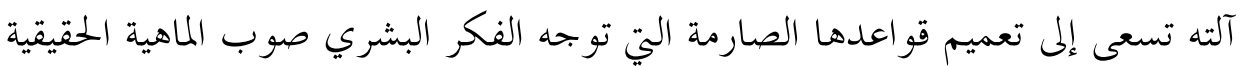

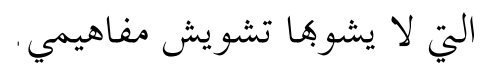

واصطلاح المنطق المضبّب يشير إلى وجود نوع من العلاقة الوطيدة بين العبارة المنطقية التي اتصفت منذ نشوء علم المنطق بصرامة وحدية، وبين التشويش والغموض الذي يكتنف المسائل التي يتعامل معها.

ولعل أحد العقبات التي ستشخص أمامنا في هذه المعالجة، ستكمن في كيفية تبسيط مفردات الحوسبة الذكية التي تم توظيفها في المنطق المضبّب بصيغ رياضية معقدة

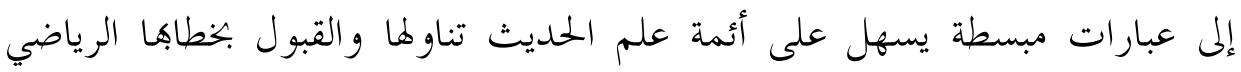

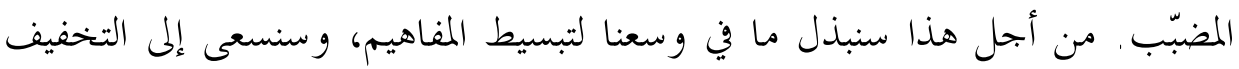
من صعو بة تضاريس مقو لاتها وصياغاها الرياضية الصرفة لكي نصل مجتمعين، إلى قناعة

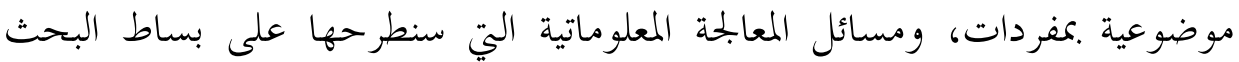
ضمن هذه الدراسة.

بصورة عامة يعد المنطق المضبّب، جسراً يتجاوز الفجوة المقيمة بين عتبة الدقة

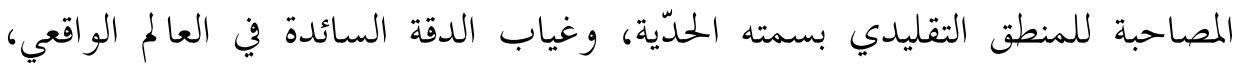

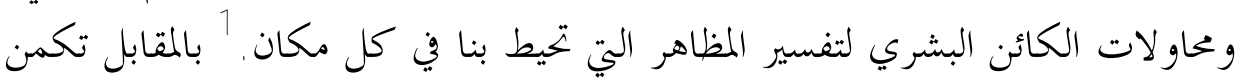

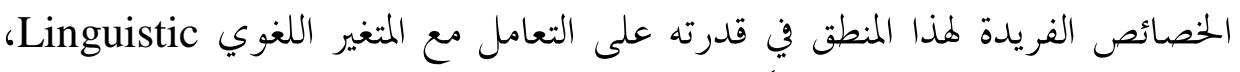

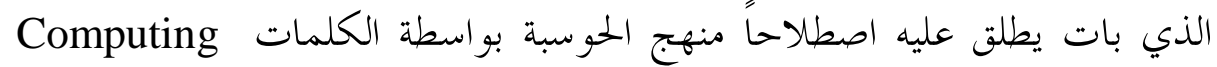
With Words و منطقية مبتكرة، لوصف الكثير من المسائل الشائكة في علومنا المعاصرة.

${ }^{1}$ Freksa, C., Fuzzy Systems in AI, In Fuzzy Systems In Computer Science, Kruse R, Gebhardt J, Palm R, eds,155-169, Vieweg, Braunschweig/Wiesbaden 1994. 
إن إحدى النتائج الكبيرة التي حققتها جهود الإنسان في اكتشاف أسرار الكون

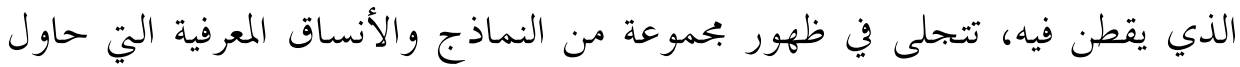

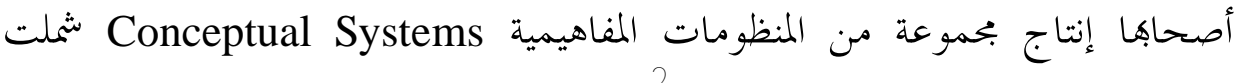
المنطق، والرياضيات، و الفلسفة، والعلم. 2

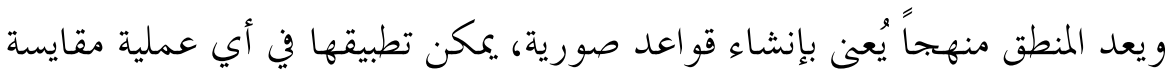
عقلانية، ننشد من خلالها الوصول إلى اليقين. وعلى هذا الأساس فإِ فإن هذا العلم يجعلنا

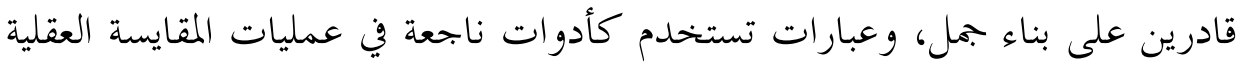

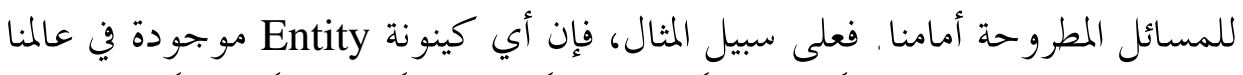

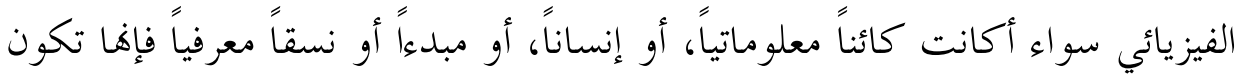
قابلة لسلسلة من عمليات المقايسة العقلانية للوصول إلى نتيجة محددة.

ويمكن أن نباشر إحدى هذه العمليات، إذا قمنا بإطلاق تسمية محددة على كينونة

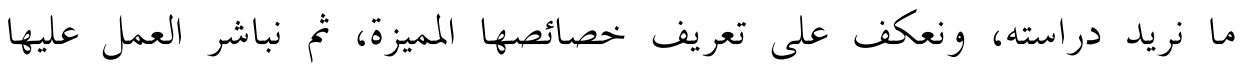

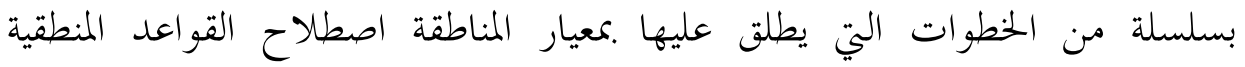
Logical Rules

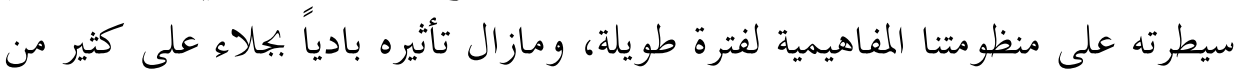
النماذج المعرفية لعلوم شتى في هذه الأيام.

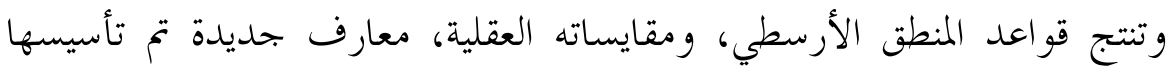

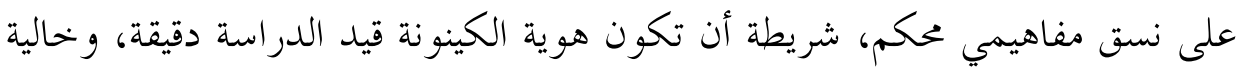
من ظاهرة غياب الصدق المنطقي للقضية. 3

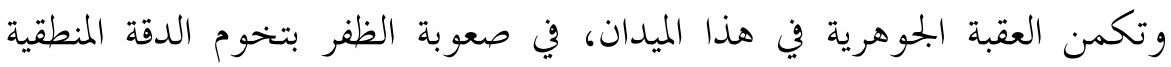

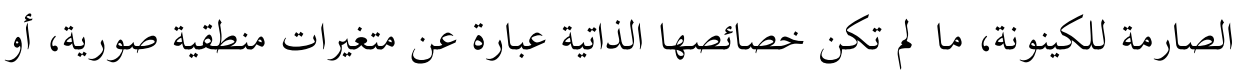

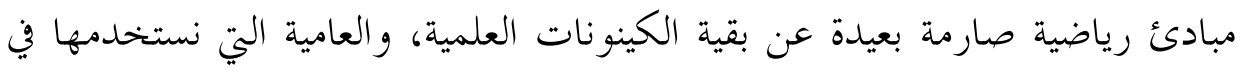

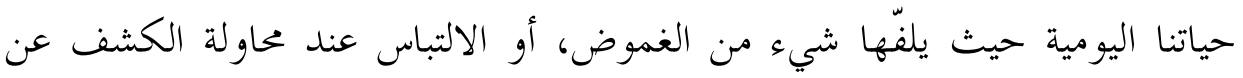

${ }^{2}$ Rouvary,D.H., Editor, Fuzzy Logic in Chemistry, Academic press, California, USA, 1997

${ }^{3}$ Casti,J.L., Searching for Certainty, Morrow, NewYork,1991. 
وعلى هذا الأساس يمكننا القول بأن علم المنطق يمتلك القدرة على معالجة القضايا المطروحة في ساحته، بيد أنه يعجز عن أداء دوره في توليد استنتاجات صادقة بصورة

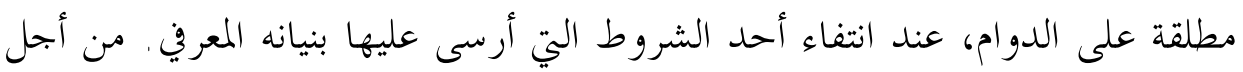

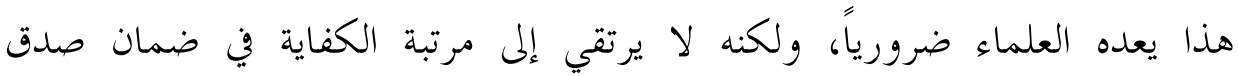

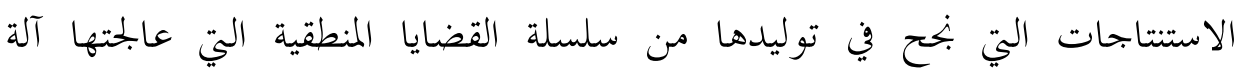
استدلاله (Oldoryd,1986)، من جهة أخرى يمكن تصنيف المعرفة التي نتعامل معها Certain في جل أنشطتنا العلمية واليومية إلى صنفين جوهريين: المعرفة اليقينية Knowledge و والمعرفة غير اليقينية Uncertain Knowledge تسود المعرفة اليقينية في حدود الحقول البحردة عندما تكون الحقائق والقواعد مسلمات مطلقة تتطابق بصورة كلية مع الواقع. بالمقابل فإن المعرفة المستمدة من حياتنا

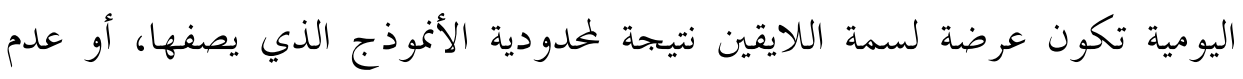
كفاية الأدوات المستخدمة لاكتساها، وقد ينشأ اللايقين عن التأثيرات الإحصائية، التي

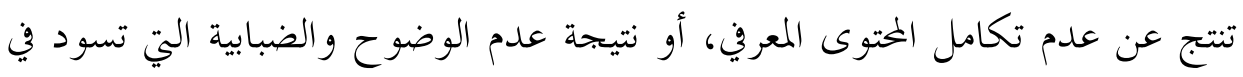

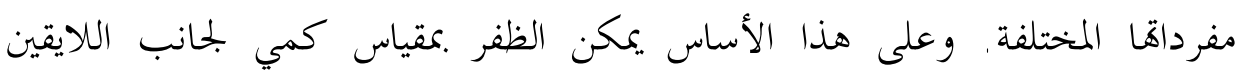
المصاحب للمعرفة بتوظيف الطرق الإحصائية التي تحاول إزالة الضوضاء التي تسري في كياها، أو باستخدام نماذج رياضية كمية توظف آليات وضعية Empirical.

لقد تزايد الاهتمام خلال القرون الثلاثة الأخيرة، .مسألة اللايقين التي تكتنف الكثير من المسائل الرياضية والعلوم الصرفة، وقد توجهت أنظار الباحثين إلى توظيف

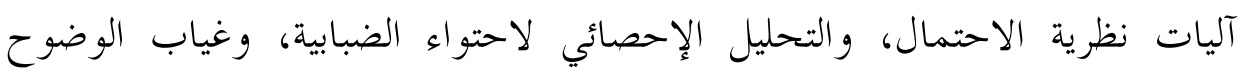
الملتصق بالخطاب العلمي .كمتلف بحلياته المعرفية.

${ }^{4}$ Russel, B., Our Knowledge of The External World, Allen \& Unwin, London, 1914.

${ }^{5}$ Oldoryd, 1986.

${ }^{6}$ Freksa, C., Fuzzy Systems in AI, In Fuzzy Systems In Computer Science, Kruse R, Gebhardt J, Palm R, eds,155-169, Vieweg, Braunschweig/Wiesbaden 1994. 
وقد برز اصطلاح الاختلاط والتشويش Chaos، لكي يعزز موقف نظرية

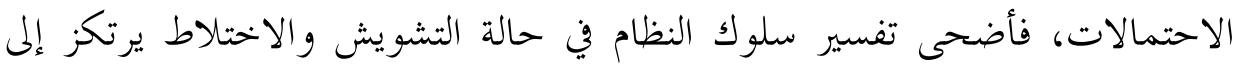

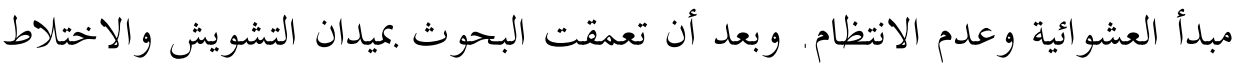
ظهرت محاولات جديدة، لوضع حد فاصل بين هذه الظاهرة، وبين السلوك العشوائي

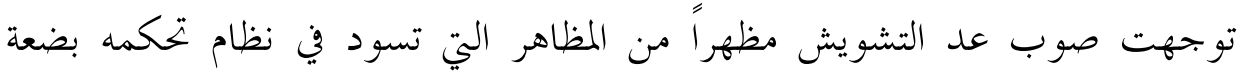

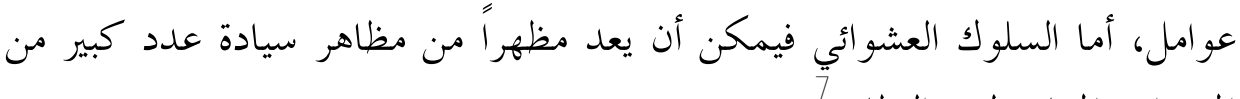

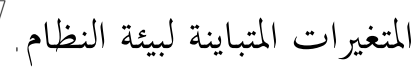

وبنم عن ابتكار المنطق متعدد القيم Multi-valued Logic حصول تغيير

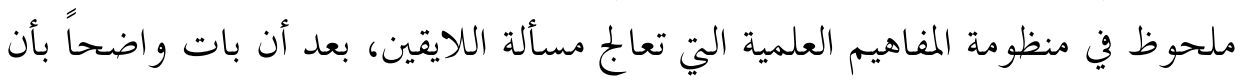

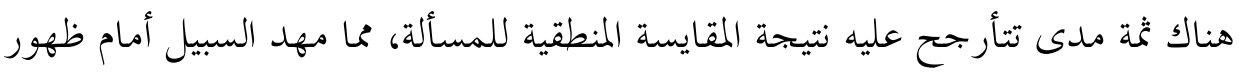

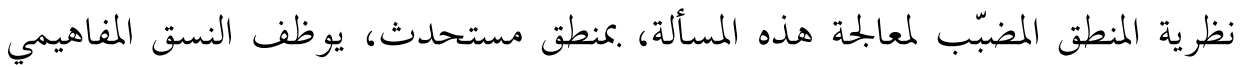

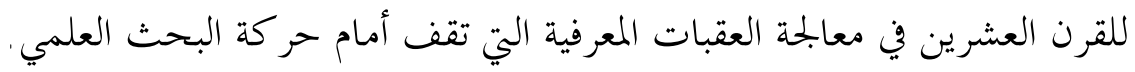
ولا يكاد يخفى علينا جميعاً ما قد يحمله الخطاب العلمي من مفردات، تتسم

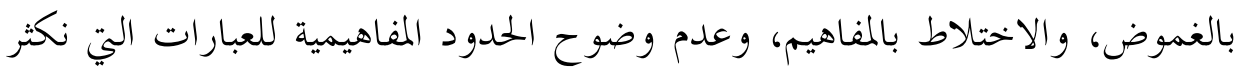

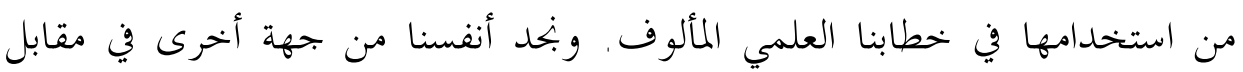

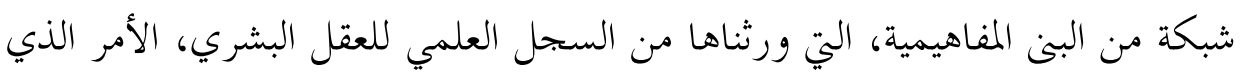

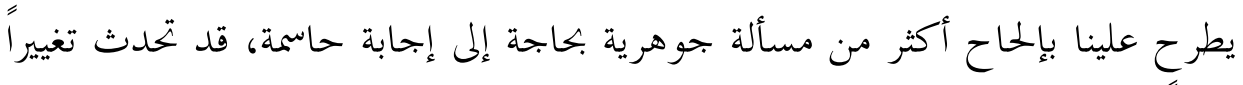
كبيراً في أنساقنا المفاهيمية، وتغير الكثير من مفردات الخطاب مناب العلمي المعاصر.

$$
\text { ومن هذه المسائل: (1) - (1) }
$$

(1) عجز المنطق الأرسطي عن احتواء المسائل العلمية المعاصرة وتعاملها مع المعائ مفردات الحياة اليومية التي لا تتسم بالوصف الصفي عن الصارم لهذا المنطق الصوري.

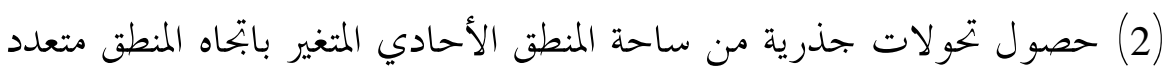

القيم، وبأنساق مختلفة.

7 Rouvary,D.H., Editor, Fuzzy Logic in Chemistry, Academic press, California, USA, 1997 
(3) سيادة القدرة لدينا على التعامل مع مسائل ذات صلة بالواقع الميداني والتعامل معها بمنظور يبتعد كثيرًا عن النظريات الاحتمالية التقليدية.

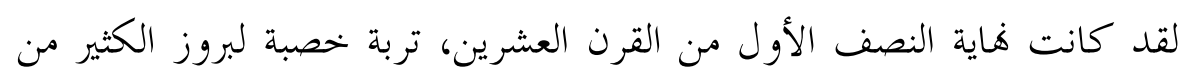

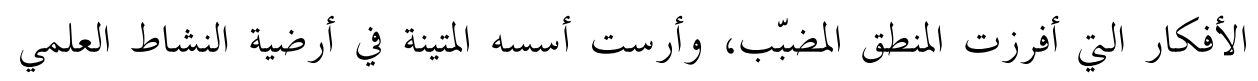

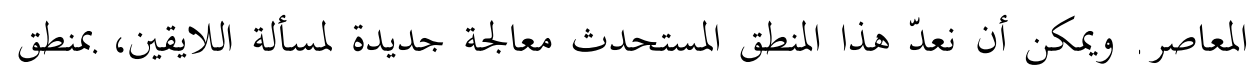

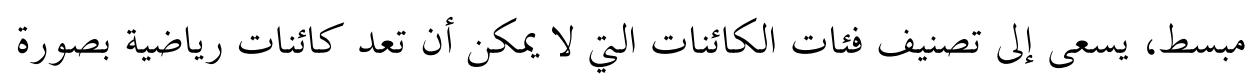

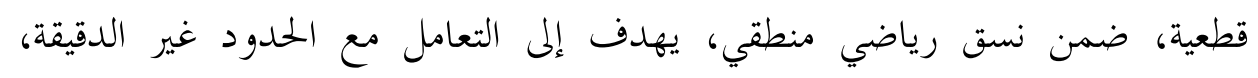

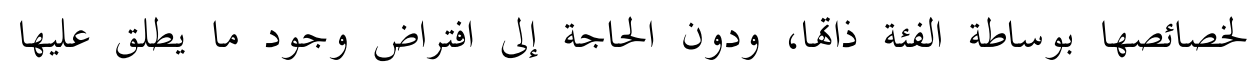
المتغيرات العشو ائية.

\section{الأسس الرياضية والمنطقية لأنموذج المنطق المضبّب:}

تبدأ تخوم المنطق المضبّب عندما تبرز أمامنا المجموعة المضبّبة Fuzzy Set كبديل

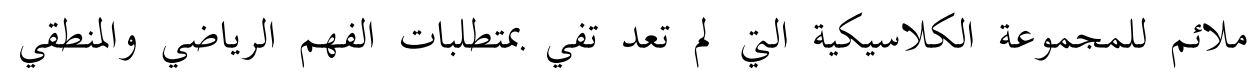

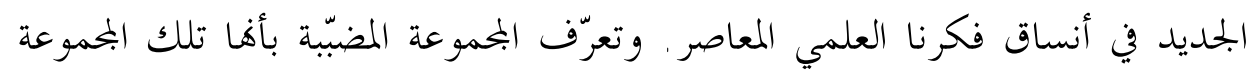

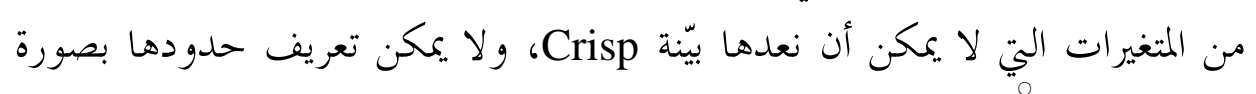
واضحة ودقيقة

ومن هذه النقطة تبرز حقيقة غياب حدود ( نعم / لا ) الصارمة في دائرة تعاملنا

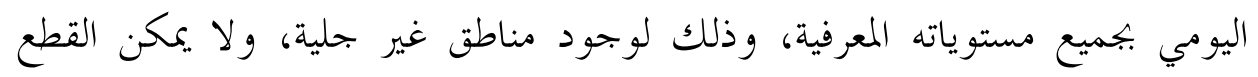

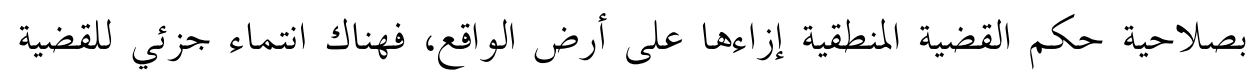

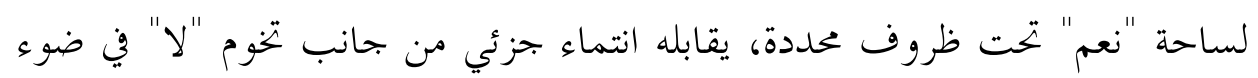
محددات الواقع.

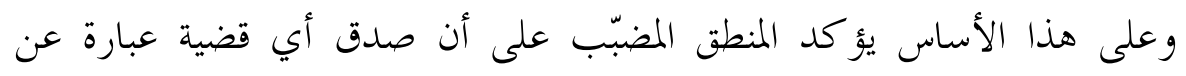

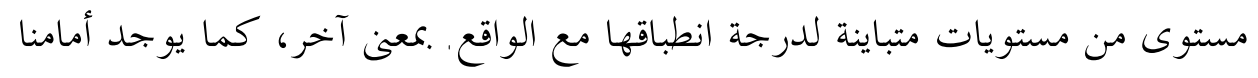

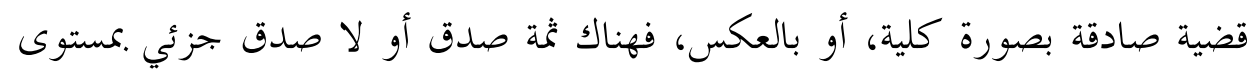




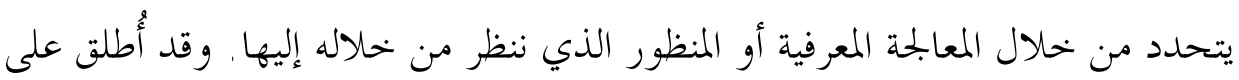

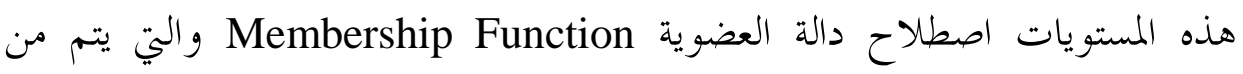

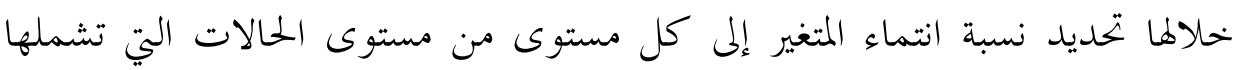
المعالجة المعرفية.

تتألف الصيغة الرياضية الخاصة بوصف المحموعة المضبّة من المعادلة الآتية: (1) $x \in X \quad A=\left\{\left(x, \mu_{A}(x)\right)\right\}$,

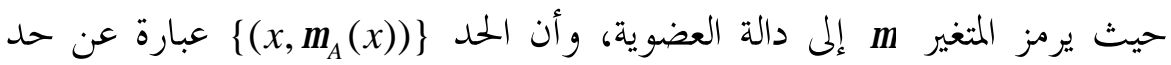
منفرد Singleton يصف متغيراً يقع ضمن البحموعة المضبّة A (Spagnolo,F.,2003). وعلى هذا الأساس تتحدد تخوم المحموعة المضبّة A عن حصيلة اتحاد جميع الحدود المنغردة التي تم وصفها بو اسطة الحد الحد

$$
\text { (2) } A=\underset{x, \in X}{Y} \mu_{A}\left(x_{i}\right) \mid x_{i}
$$

يختلف مظهر الوصف الرسومي لدالة العضوية اعية Membership Shape في ضوء

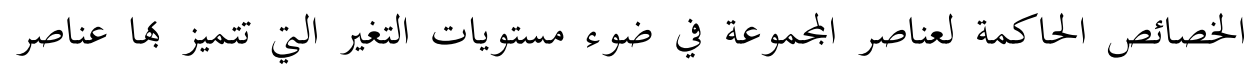

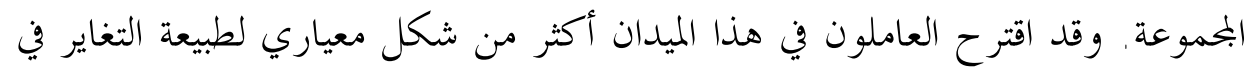

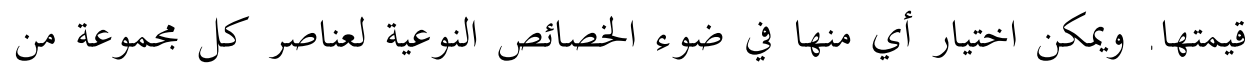
البحموعات المضبّة التي نتناولها بالدراسة والتحليل فو (Bezdek, J.C. 1993). فإذا نظرنا إلى شكل (1) سنلاحظ بأن مستوى منخفض للمتغير المضبّب يقع بين

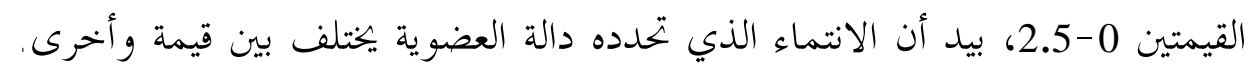

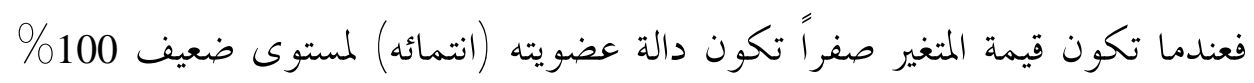

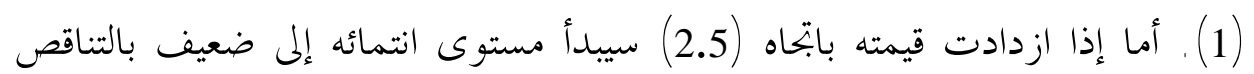

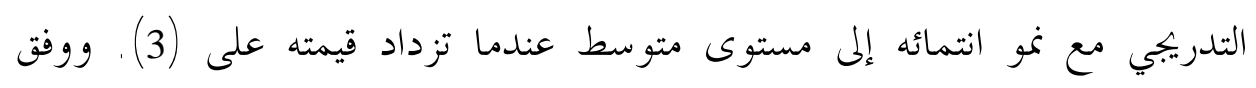


الأرضية المفاهيمية التي يطر حها المنطق المضبّب سيكون هناك بحموعة انتماءات للمتغير

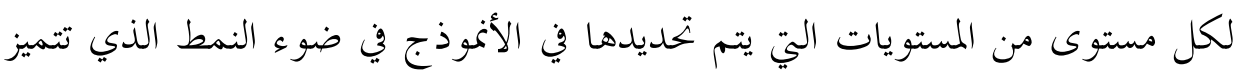
به دالة العضوية التي تصف طبيعة التغير السائد في بنيته.

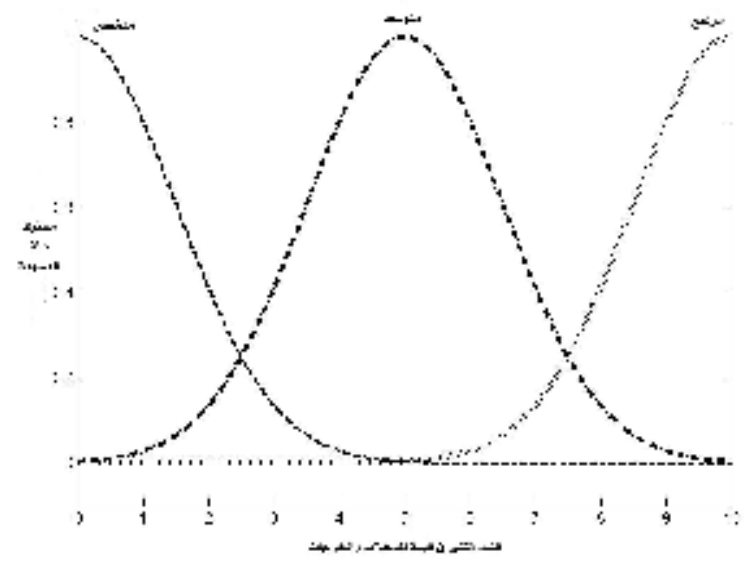

$$
\text { الشكل رقم (1) - مستويات دالة العضوية لمتغير مضبّب. }
$$

ويتألف الإطار الكلي لآلة الاستدلال المضبّب من علاقات رياضية منطقية تصف مدخلات الأنموذج المضبّب Fuzzy Model ومخرجاته بواسطة بحموعة من القواعد التي تتألف صياغتها من IF .. THEN في توصيف الجانب الأيسر من معادلاها L.H.S

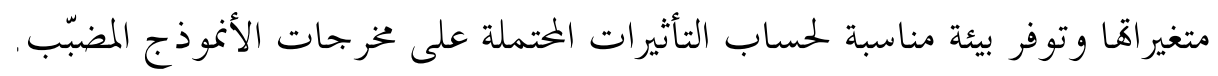
تسهم القاعدة المضبّة من هذا النوع بربط شرط تم وصفه باستخدام متغيرات

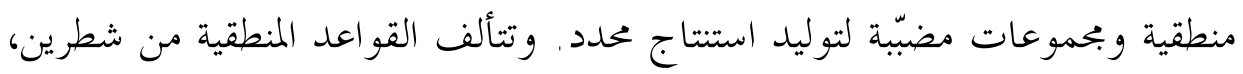
يطلق على الشطر الأول من القاعدة أو العبارة المنطقية اصطلاح ركن البيان المنطقي Premise، في حين يطلق على الشطر الثاني منها نتيجة المقايسة المنطقية Consequent. وبصورة عامة، يتألف الوصف اللغوي للقواعد المضبّة من الصيغة الآتية: (نرط) IF Condition 
تبرز مرحلة إزالة التضبيب Defuzzification كخطوة ضرورية لإعادة قولبة

القيم المضبّة التي أدخلت في بنية النظام الرياضي والمنطقي لكي تتلاءم مع الآليات السائدة في أنموذجه (Kartalopoulos,1996). وتسهم هذه العملية في إنتاج قيم

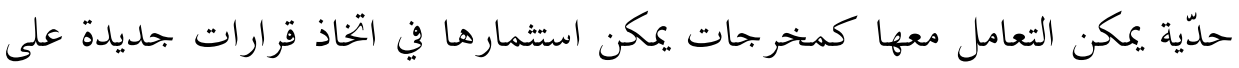
أرض الواقع انظر الشكل رقم (2).

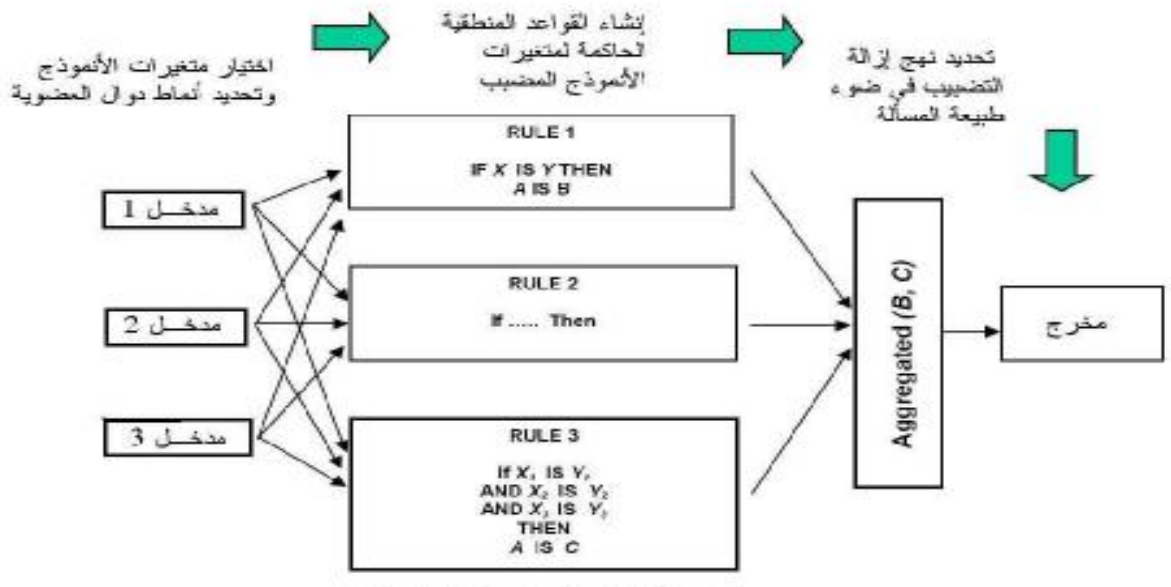

عراحسل إنشاء أنموذج المنطق المضبب

الشكل رقم (2) - البنية الرياضية و المنطقية لأنموذج المنطق المضبّب.

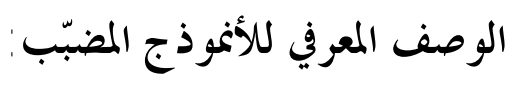

تعد عملية الوصف المعري فnowledge Representation للأنموذج المضبّب الأساس المتين الذي يؤسس الخلفية المفاهيمية لتعامل هذا الأنموذج مع الظواهر التي نحاول من خلاله تعميق فهمنا بماهيتها، وتمهيد آلية مناسبة للتعامل معهية

$$
\text { واستثمار ها. } 10
$$

كما تستخدم آلة الاستدلال المعرفي المضبّب Fuzzy Inference Engine بوصفها أداة توظف آليات المنطق المضبّب التي تبتدئ بالمتغير المضبّب، وتنتهي بسلسلة

${ }^{10}$ Schneider, M, A. Kandel , G. Langholz \& G. Chew, Fuzzy Expert System Tools, John Wiley, USA, 1996 
المتغيرات السائدة بين البمموعات المضبّبة، التي يشدّ أزرها جميعاً هيكل متين لعملية الاستدلال المنطقي الذي نشأ في هذه البيئة الجديدة.11.

وتتألف هذه الآلة من بحموعة خوارزميات تستخدم آلية القواعد المنطقية من نوع

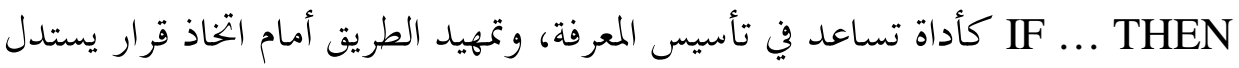

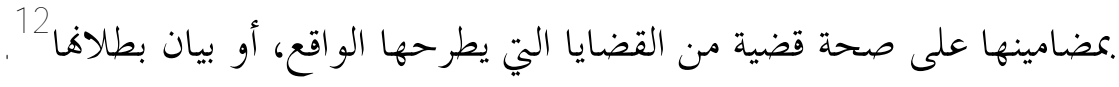

\section{الإطار الكلي لآلة الاستدلال المضبّب:}

يتألف الإطار الكلي لآلة الاستدلال المضبّب من علاقات رياضية / منطقية تصف

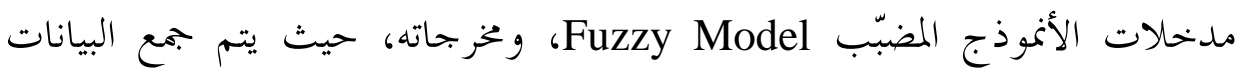

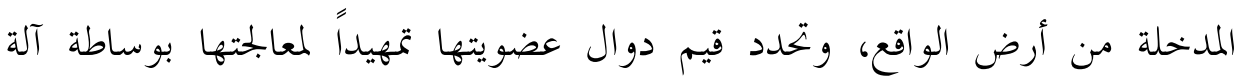

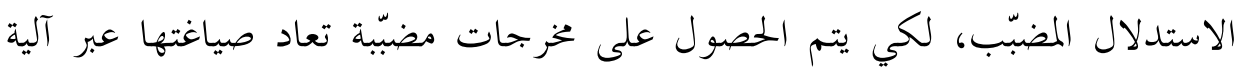

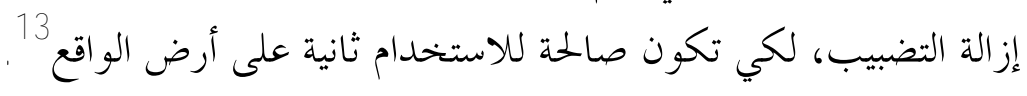
وتتتل القو اعد المضبّبة دوراً فاعلاًا في تسيير دفة المعالجات التي تسري داخل هيكل

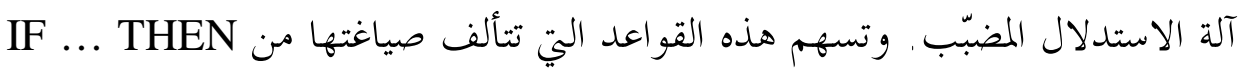

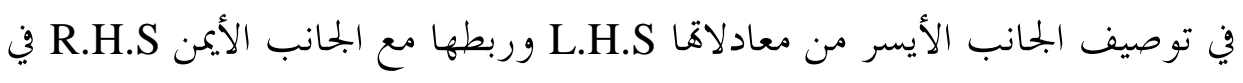
ظل شبكة من العلاقات التي تحكم متغير اها.

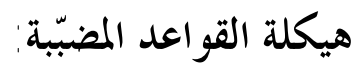

تسهم القاعدة المضبّة من نوع IF.....THEN بر بط شرط تم وصفه، باستخدام

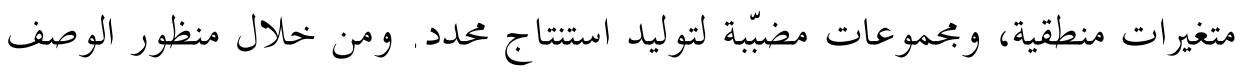

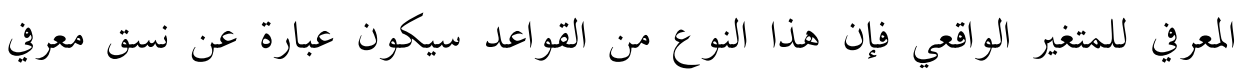

${ }^{11}$ Yen,J, \& R. Langari, Fuzzy Logic: Intellect, Control,\& Information, Prentice Hall, USA, 1999.

12 Kruse, R., 1997.

${ }^{13}$ Berkan,R.C., \& S.L. Trubatch, Fuzzy Systems Design Principles, IEEE Press, USA, 1997. 
يهدف إلى اقتناص المعرفة التي تعاني من غياب دقة المضمون. 14 من أجل هذا فإن

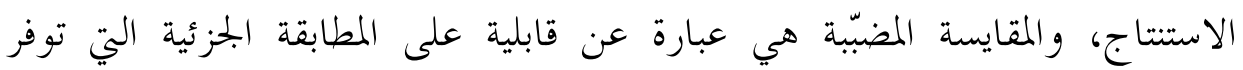

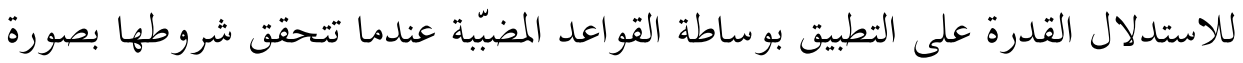
جزئية.

ويكمن التحدي في التعامل مع هذا النوع من المقايسات المنطقية المبتكرة نتيجة

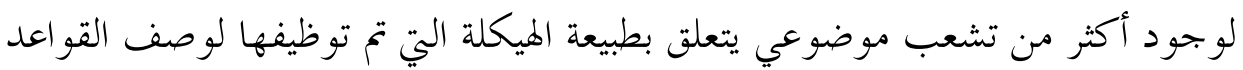

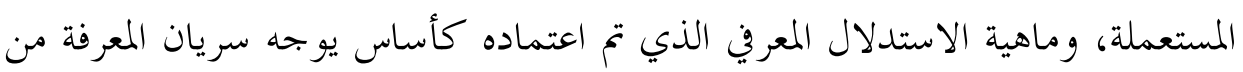
خلال الهيكل المنطقي والرياضي لهذه القو اعد. 15 وتحتل الصياغة اللغوية دوراً جوهرياً، في النظم المضبّة التي تستخدم القواعد

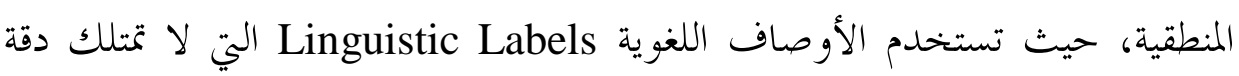
كافية في وصف الظاهرة بوصفها إحدى اللبنات الرئيسة لصياغة المقايسة المنطقية والرياضية المطلوبة. وتسهم هذه الكلمات في تسهيل عملية استخلاص، وتوثيق المعرفة البشرية في صيغة صريحة مفصّلة.

وتتألف القواعد المنطقية من شطرين، يطلق على الشطر الأول: اصطلاح؛ ركن

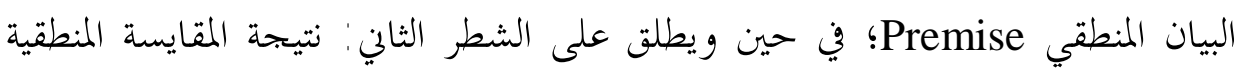
Consequent

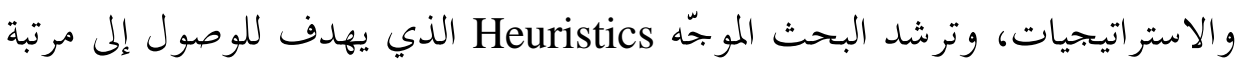

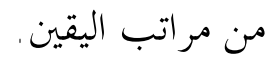

وبصورة عامة يتألف الوصف اللغوي للقواعد المضبّبة من إحدى الصيغتين الآتيتين:

${ }^{14}$ Yen,J, \& R. Langari, Fuzzy Logic: Intellect, Control,\& Information, Prentice Hall, USA, 1999.

${ }^{15}$ Babuska, R., Fuzzy Systems, Modeling and Identification, Delft University of Technology, Department of Electrical Engineering Control Laboratory, Mekelweg , GA Delft, The Netherlands, 2000 
THEN Consequence (شرط: (نتيجة) الصيغة الأولى: IF Condition

$$
\text { حيث يتم تتثيل الشرط والنتيجة باستخدام صيغ منطقية. }
$$

حيث يتم تمثيل النتيجة بصيغة التضمن Implication.

\section{إزالة النضبيب Defuzzification}

تظهر مرحلة إزالة التضبيب كخطوة ضرورية لإعادة قولبة القيم المضبّبة التي

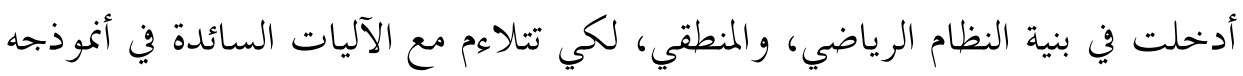

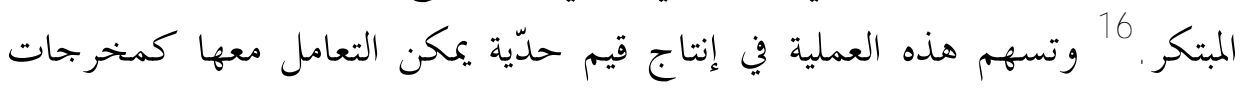
يمكن استمارها في اتخاذ قرارات جديدة.

إن عملية اختيار قيمة واحدة من بحموعة قيم مضيّبة ليس بالأمر الهيّن 17 و ويتطلب

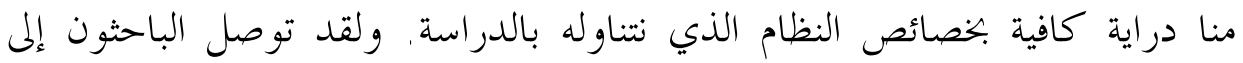

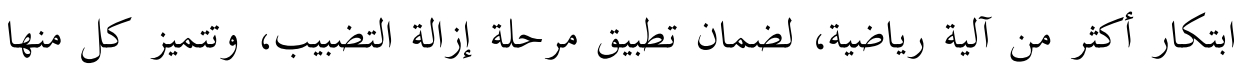

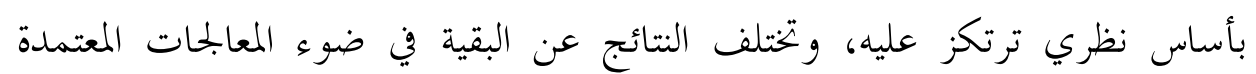
لتحقيق ذلك. 18

\section{ثانياً: أوجه التقارب بين المنطق المضبّب ومنطق نقد مراتب الخدّّثين:}

إن إحدى المقولات الجوهرية التي صدع هـا المنطق المضبّب في ساحة تقنيات

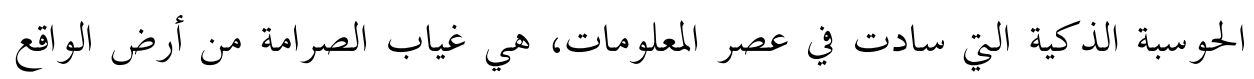

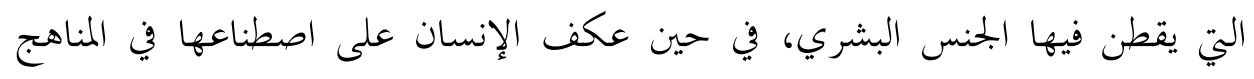

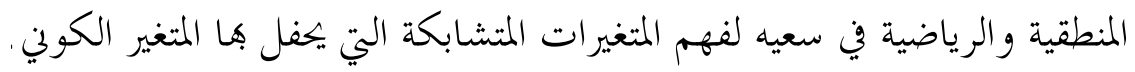

${ }^{16}$ Kartalopoolos, S.V., Understanding Neural Networks and Fuzzy Logic: Basic Concepts and Applications, IEEE Press, 1996.

17 Berkan,R.C., \& S.L. Trubatch, Fuzzy Systems Design Principles, IEEE Press, USA, 1997.

${ }^{18}$ Vernon ,J., Fuzzy Logic Systems, Fuzzy Systems White Paper, 1999, Available At: http://www. control-systems-principles.co.uk. 
ويبدو واضحاً للعيان وجود تقارب كبير بين الأرضية المفاهيمية لعلم الحديث النبوي من جهة والمنطق المضبّب من جهة أخرى، لا بل قد نصل في بعض الأحيان إلى لى

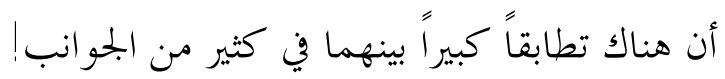

لقد اعترف جل أئمة الحديث وجهابذة نقاده بأن علم الحديث يعتمد على موارد ظنية تصعب معها إمكانية القطع بصحة ما ذهبو ا إليه، لأن معالجة مسائل الحديث تقع في دائرة ظاهر الأمر، فربما تصح رواية الضعيف، وتحفل رواية الثقة بموارد الضعف. من أجل هذا عندما تحدث أئمة الحديث عن الحديث الصحيح قالوا إذا قيل في حديث انه صحيح الإسناد، فإنه عبارة عن حكم ظي استند إلى قاعدة اتصال سنده،

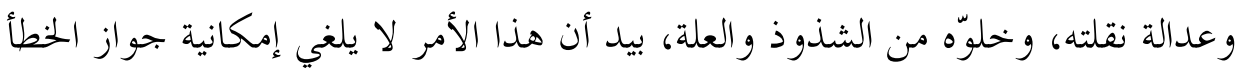
والنسيان على الثقة في رواية بذاها. 19

أما مسألة نقد الرجال وتحديد مراتبهم فموضوع يشوبه الكثير من الأمور الظنية التي تنشأ عن أكثر من مورد يلقي بظلال اللايقين على القطع بصرامة الحكم ووضوح أدلته بصورة قطعية.

إن العدالة، والتقوى، والمرووة، والحفظ، والإتقان سمات إنسانية تفتقر في تحديد تخومها إلى حدود اصطلاحية موضوعية ذهب أئمة الشأن إلى أكثر من مذهب عند بياها. وعلى هذا الأساس بنحد أكثر من تعريف، وبحموعة كبيرة من الأقوال المنقولة في تحديد دلالة هذه الصفات النوعية، التي اصطلح علماء الحديث عليها لكي يمهدوا

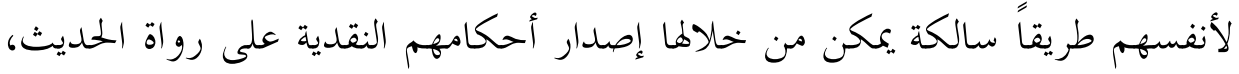
وحفظ الإرث النبوي من موارد الضعف و الوضع. ومن جهة أخرى، فإن الجوانب الإنسانية ذات الصلة بهوية المحدّث تبقى أمراً ظاهراً لا يمكن الولوج في أعماقه، مما يفرض علينا استخدام منهج المقاربة بين بحموعة الإسلة

19 السيوطي، جلال الدين عبد الرحمن بن أبي بكر، تدريب الراوي في شرح تقريب النواوي، المكتبــة العلميـة، بيروت، 1976. 
من السلوكيات التي يمارسها في البيئة العلمية والاجتماعية، ومحاولة توصيفها ضمن

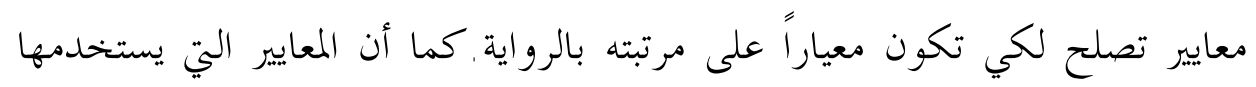

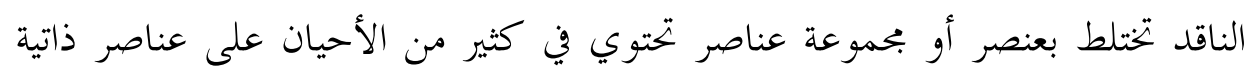

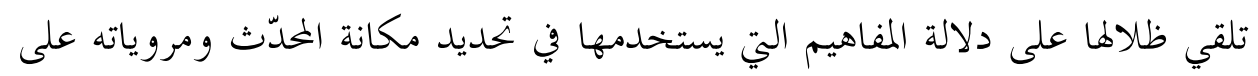

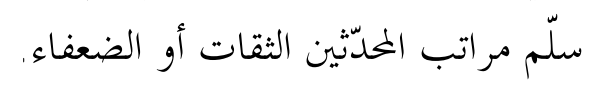

إن هذه الأرضية المفاهيمية الخصبة قد منحت أئمة الحديث ونقاد الرجال فرصة

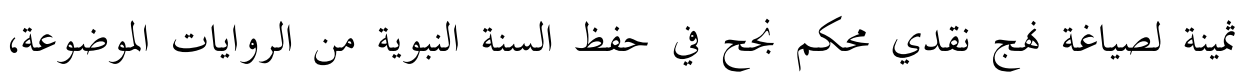

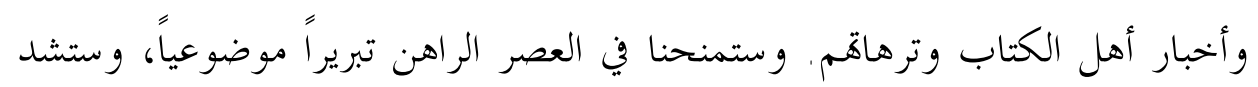

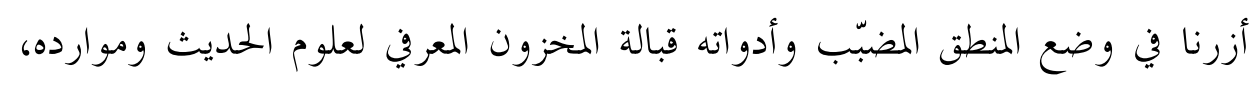

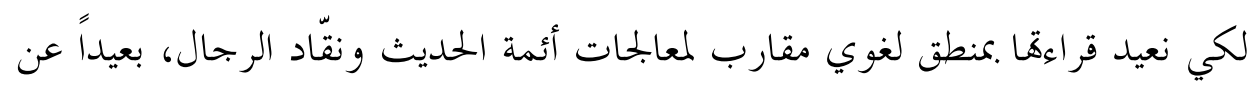

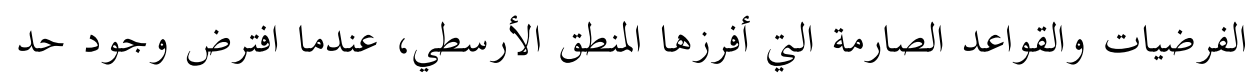

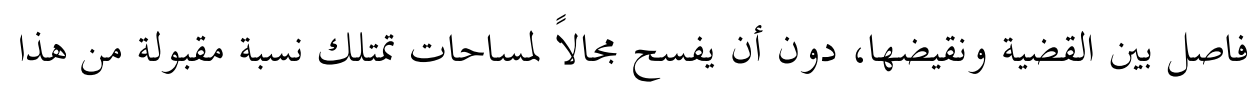

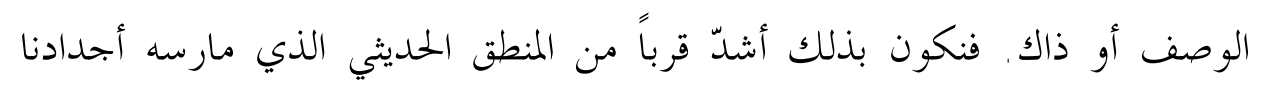

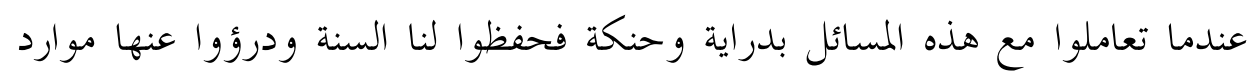

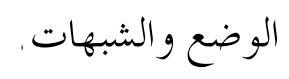

\section{ثالثاً: إعادة تشكيل قو اعد نقد الرجال بمعيار المنطق المضبّب:}

عمد أئمة علوم الحديث دراية ورواية منذ بدايات نشوء علم الحديث النبوي

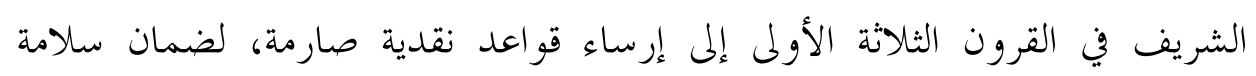

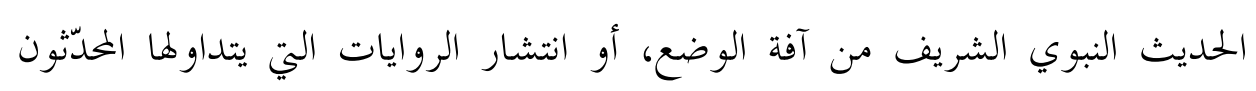
الضعفاء و المثرو كون.

وقد عولجت المسائل بمنطق حديثي صرف أفرزته الآلة المعرفية الخصبة التي نشأت 
في تربة الشريعة الإسلامية، وغذّةّا أدوات اللغة العربية التي حددت معالم الصدق في

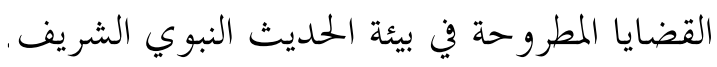

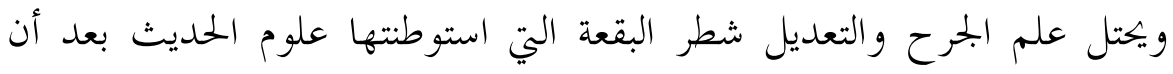

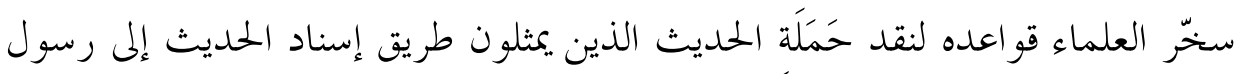

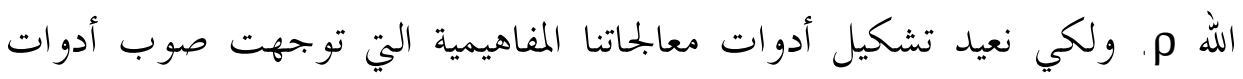

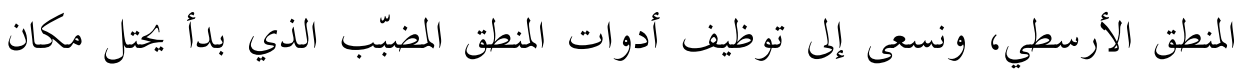

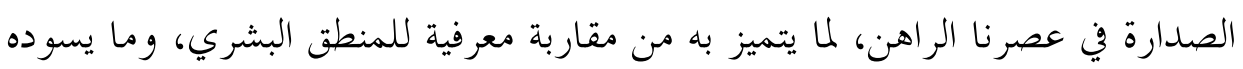

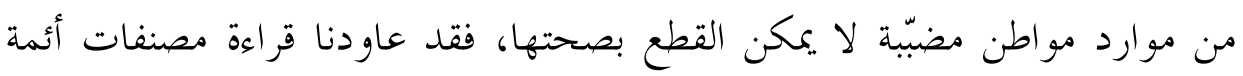

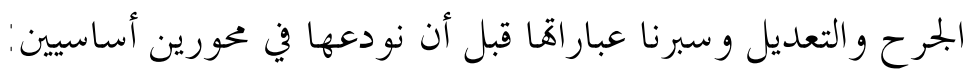

المحور الأول: شروط نستخدمها كمتغيرات تصف مدخلات الأنموذج الرياضي

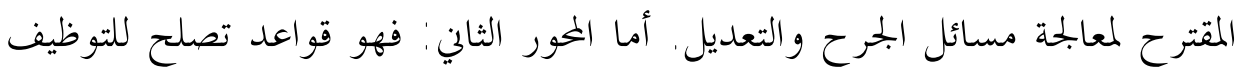

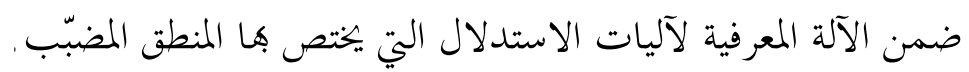

ويظهر في الجحدول رقم (1) أهم الشروط التي سنستخدمها، بوصفها مدخلات

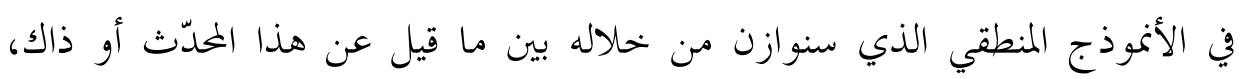

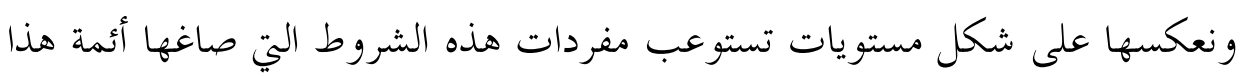

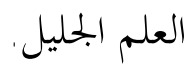


الجدول رقم (1) المتغيرات الحديثية التي استخدمت كمدخلات في الأموذج المقترح.

\begin{tabular}{|c|c|c|c|c|}
\hline \multicolumn{4}{|c|}{ مستويات دالة العضوية لكل متغير } & المتغير \\
\hline غير متمكن من علمه & عالم في تقو اه & تعصب لم لديه آفة & إمام في علمه & السمات العلمية للناقد 20. \\
\hline \multicolumn{2}{|l|}{ مبهـم } & \multicolumn{2}{|c|}{ مفسر } & سبب الجرح و التعديل 21. \\
\hline التفصيل & \multicolumn{2}{|c|}{ تقديم التعديل } & تقديم الجرح & تعارض الحكىم 22. \\
\hline وجود تعارض شديد & \multicolumn{2}{|c|}{ |تفاق مع وجود خلاف } & متفق عليه & اتفاق الأئمة 23 \\
\hline متساهل & \multicolumn{2}{|c|}{ متو سط } & 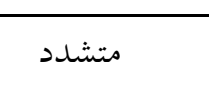 & موقف الناقد 24. \\
\hline يختص بصفة دون غيرها & عصبية & 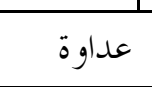 & معاصرة & التعنت في الجرح 25. \\
\hline العقدي أو الفقهي بالمذهب & \multicolumn{2}{|c|}{ 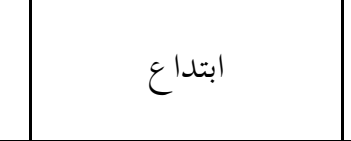 } & تشيّع & الاختلاف بالمذهب 26. \\
\hline يروي ما يخالف بدعته & \multicolumn{2}{|c|}{ لا يدعو إلى بدعته } & داعية لبدعته & آفة الابتداع 27. \\
\hline بحاجة إلى دراسة & \multicolumn{2}{|c|}{ متفق على مرتبته } & مرتبة مطلقة & محصلة الحكم. \\
\hline
\end{tabular}

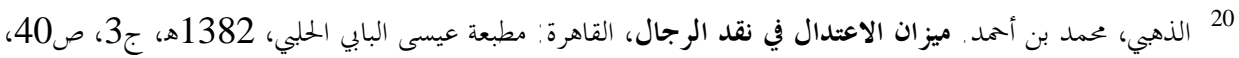

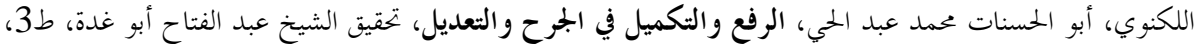

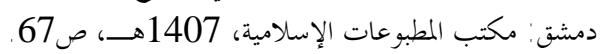

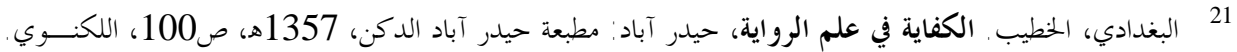

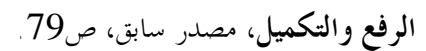

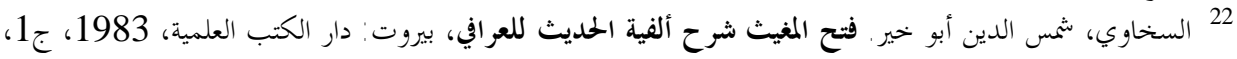

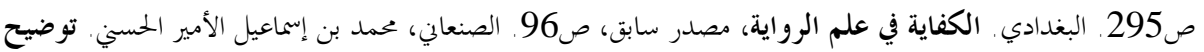

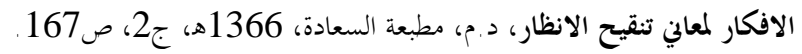

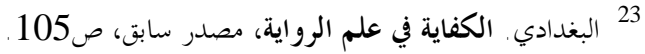

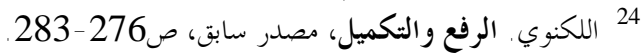

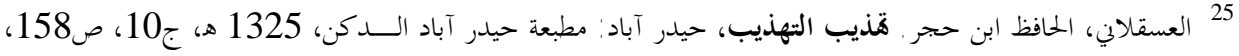

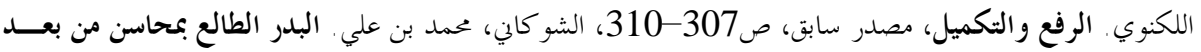

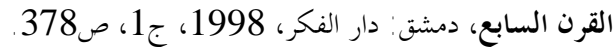

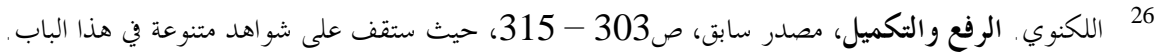

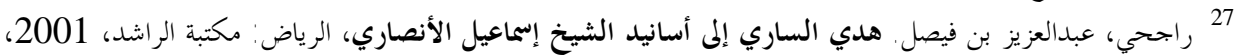

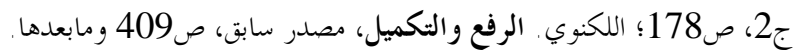


لقد قام أئمة الجرح و التعديل بحبك مفردات المتغيرات الحديثية ضمن نسيج محكم، تطور مع مرور الوقت إلى منطق أصيل متماسك يمتلك أرضية نقدية رصينة قادرة على إنى

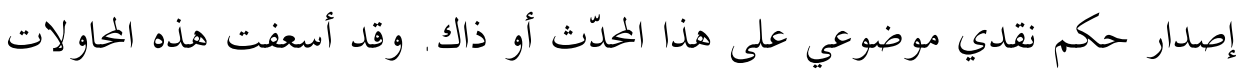
الحصيلة الميدانية لأقوال جهابذة نقاد الرجال وصيارفة الحديث التي أودعوها في كتبهم، أو تضمنتها المصنفات الخصبة هذذا المضمار الكريم.

ولا نستطيع ادعاء شمول هذه الدراسة لجميع القواعد التي وظفها أئمة الجرح و التعديل في عمليات نقد الرجال، وصيرفة خلفيتهم الحديثية، ولكنا بذلنا ما في وسعنا إلى لملمة عدد كبير منها لكي تكون هذه المحاولة قريبة من البيئة التي نحاول معالجتها

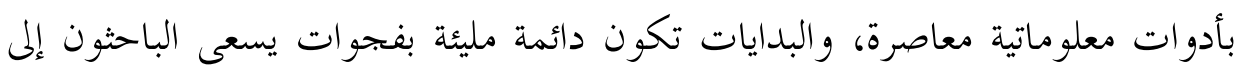
سدّها بدراسات لاحقة تثري الموضوع، وترتقي بموضوعيته، بحيث تضعه قبالة المناهج التي ألفنا استخدامها في صياغة منهج التعامل مع المفردات المطرو حة على بساط البحثث. ويظهر في الجدول رقم (2) أهم القواعد ذات الصلة المباشرة بالمتغيرات التي أودعناها في الأنموذج المعلوماتي - المضبّب، ويكثر استخدامها بين أئمة هذا العلم ورجاله.

الجحدول رقم (2) - قو اعد حديثية توجّه منطق المتغيرات المعتمدة.

\begin{tabular}{|c|c|}
\hline قو اعد حديثية منتخبة & المتغير \\
\hline 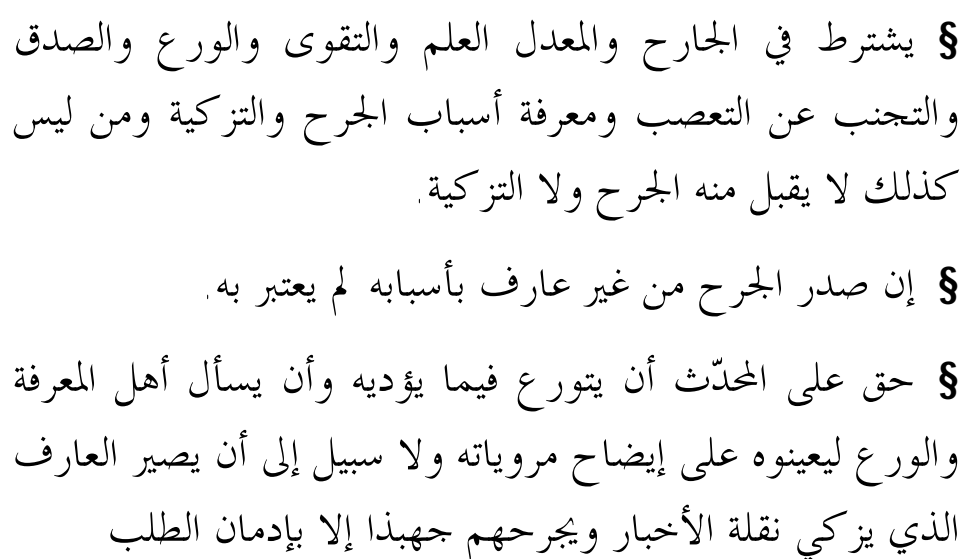 & السمات العمية للناقد. \\
\hline
\end{tabular}




\begin{tabular}{|c|c|}
\hline قو اعد حديثية منتخبة & المتغير \\
\hline 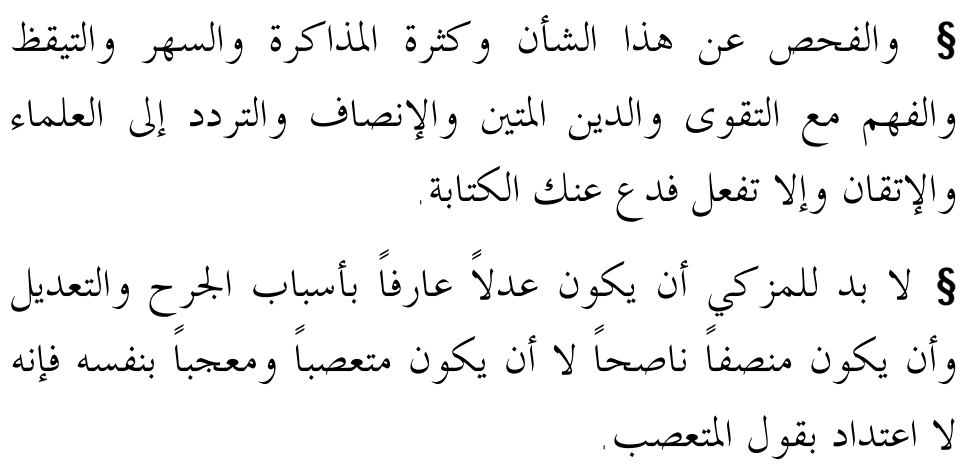 & \\
\hline 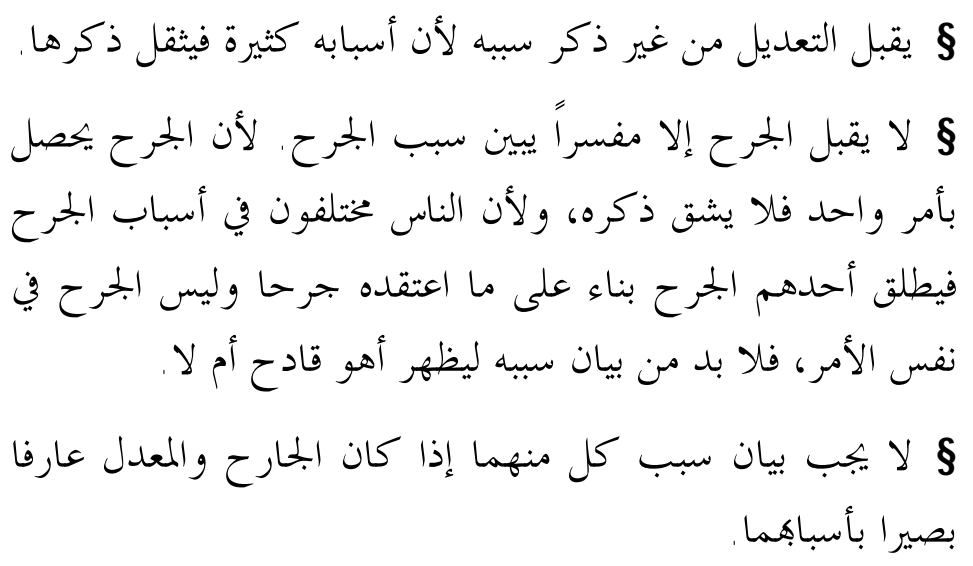 & \\
\hline 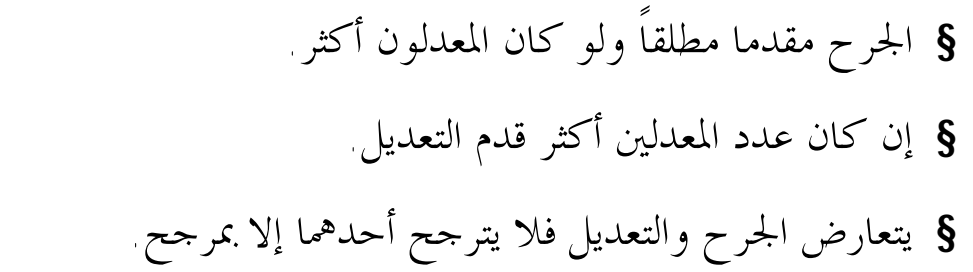 & \\
\hline 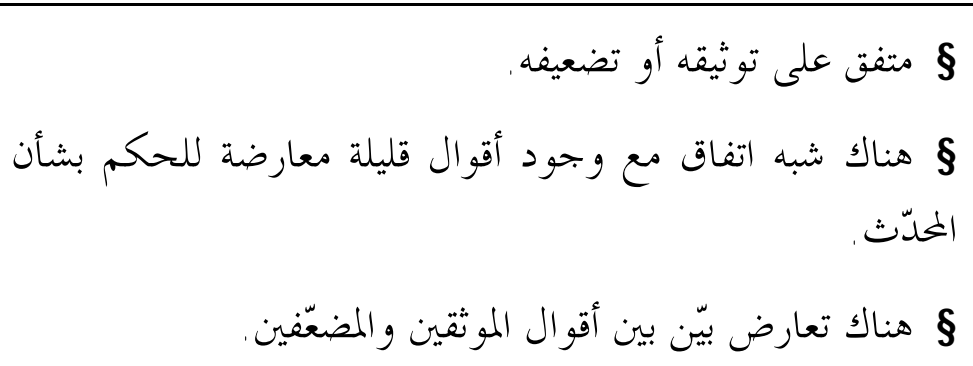 & اتفاق الأئمة. \\
\hline ق قسم منهم متعنت في الجرح متثبت في التعديل يغمز الراو & 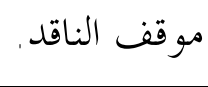 \\
\hline
\end{tabular}




\begin{tabular}{|c|c|}
\hline لد حديثية منتخبة & المتغير \\
\hline 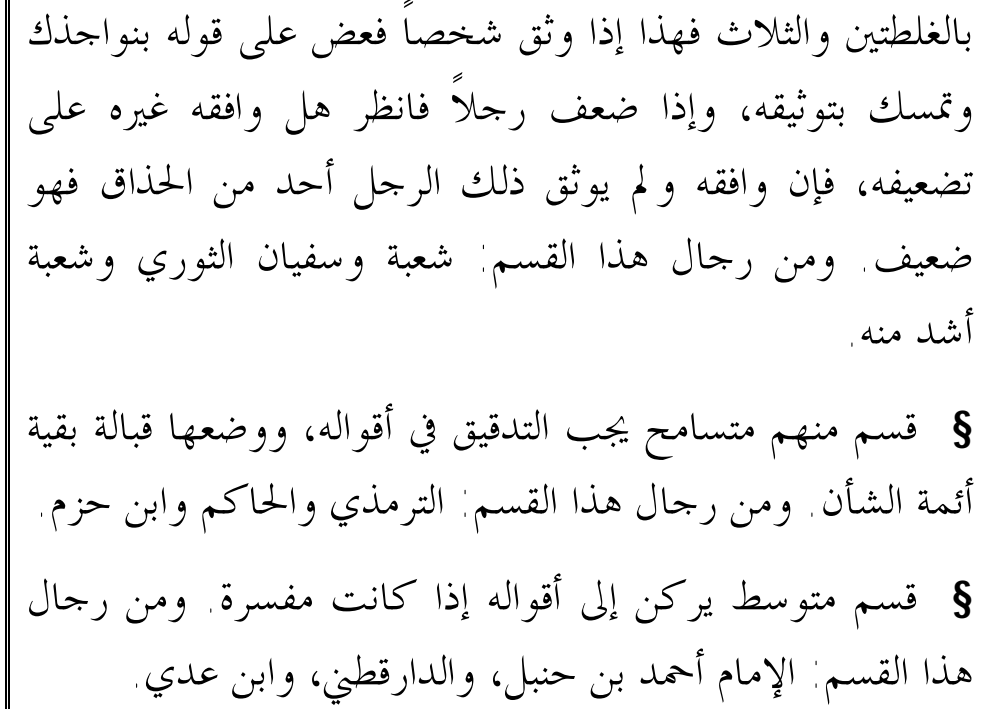 & \\
\hline 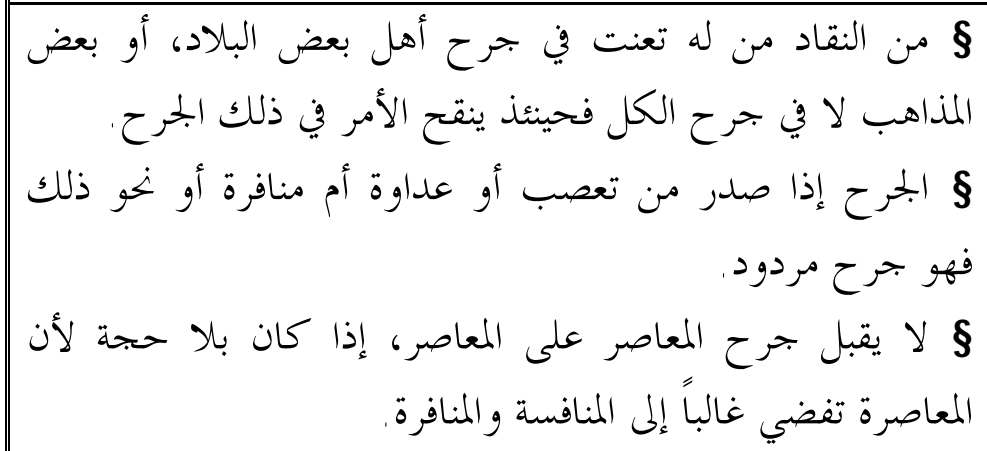 & التعنت \\
\hline و التنقير عن سبب الجرح. & الاختلاف \\
\hline 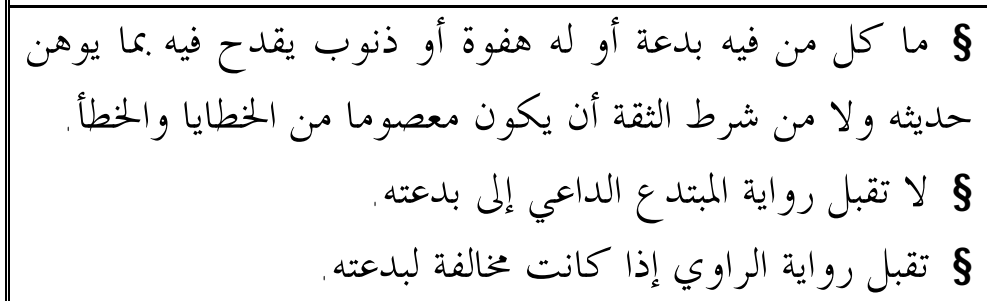 & \\
\hline
\end{tabular}




\section{رابعاً: وصف الأنموذج المنطقي المضبّب لعملية نقد الرجال:}

إن أهم الفروق المقامة بين الأنموذج المنطقي الأرسطي الذي نكثر من استخدامه

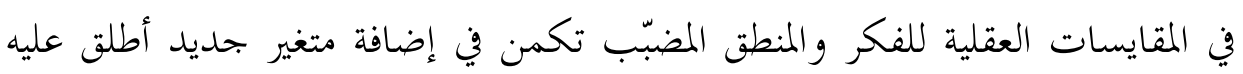

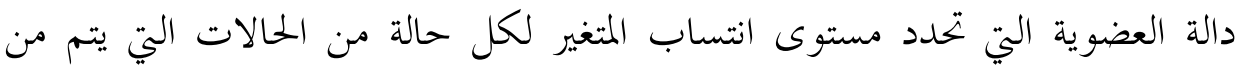

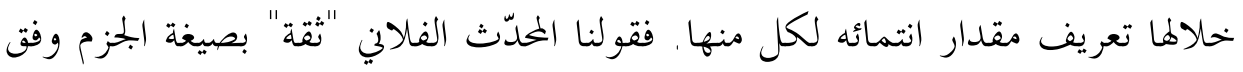

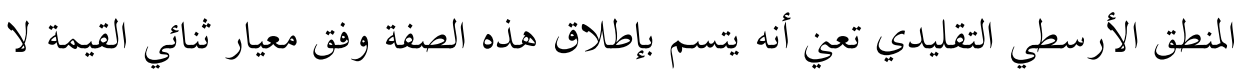

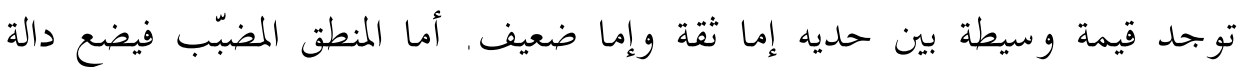

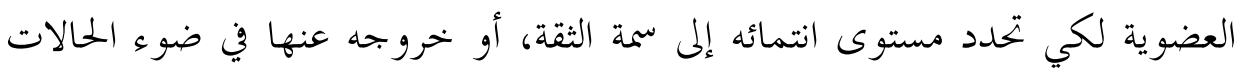

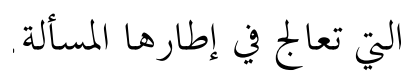

وينطبق المفهوم ذاته على المتغيرات التي يستخدمها أئمة الحديث في صيرفة الرجال

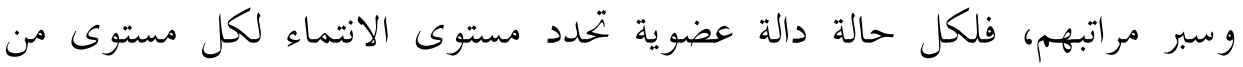

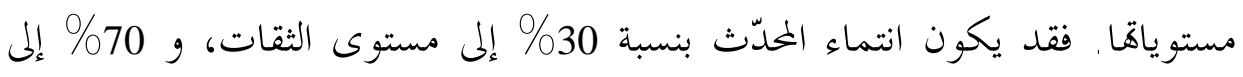

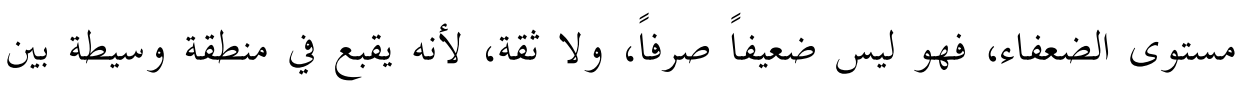

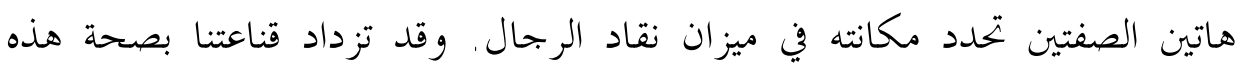

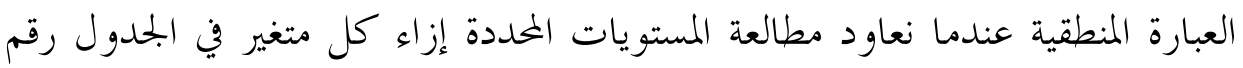

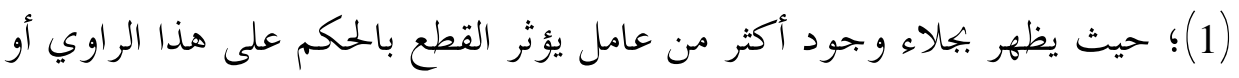
ذاك بأساليب حدية صارمة.

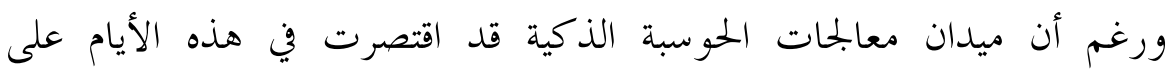

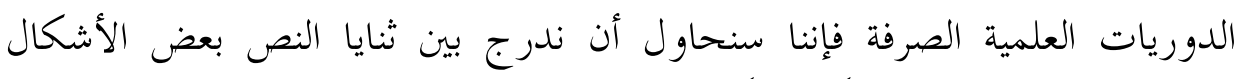

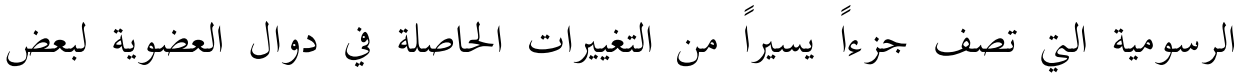

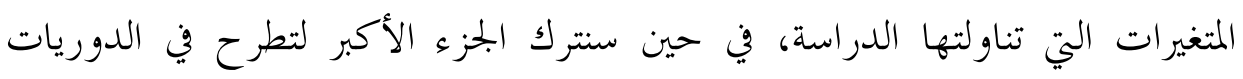

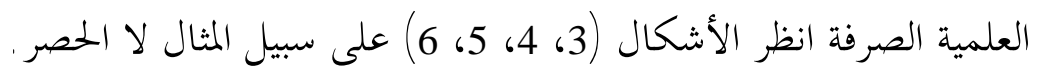


حسن مظفر الرزو

124 إسلامية المعرفة، السنة الثانية عشرة، العدد 48، ربيع 1428هـ/2007م

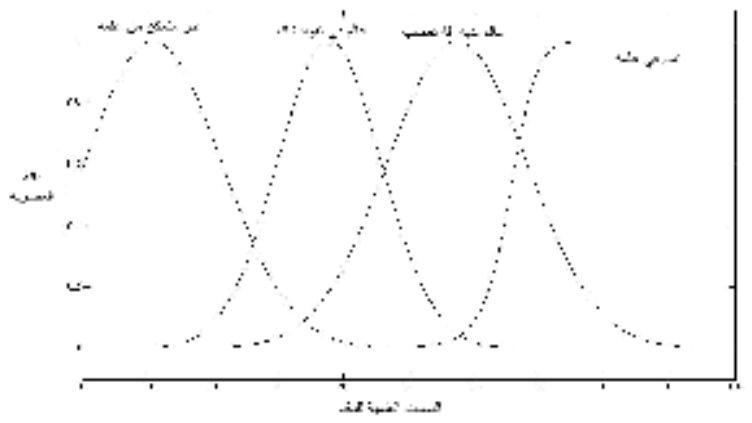

الشكل رقم (3) - ــ دالة العضوية المستخدمة في وصف مستويات السمات العلمية

للناقد.

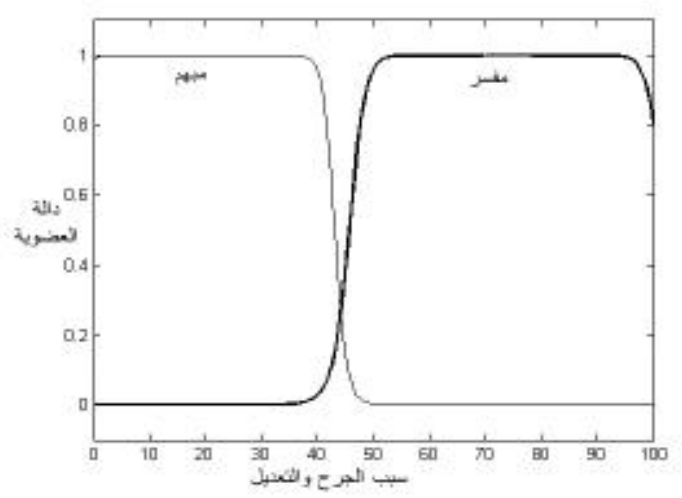

الشكل رقم (4) - ـالة العضوية المستخدمة في وصف مستويات سبب الجرح

و التعديل.

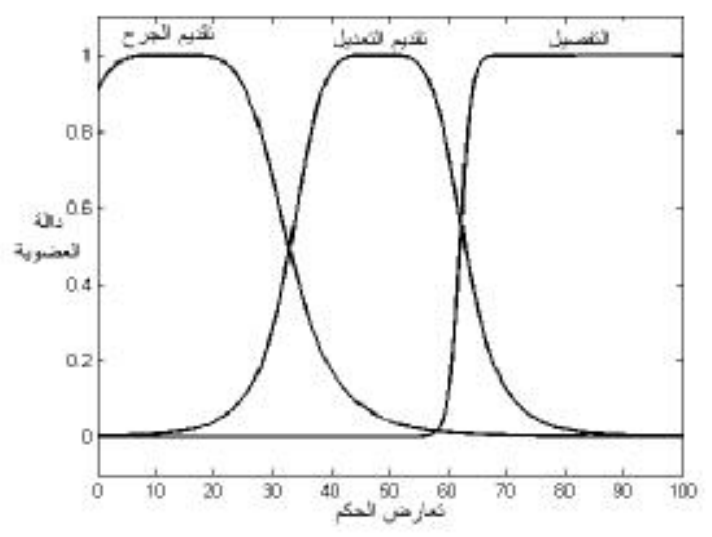


الشكل رقم (5) - ـ دالة العضوية المستخدمة في وصف مستويات تعارض الحكم.

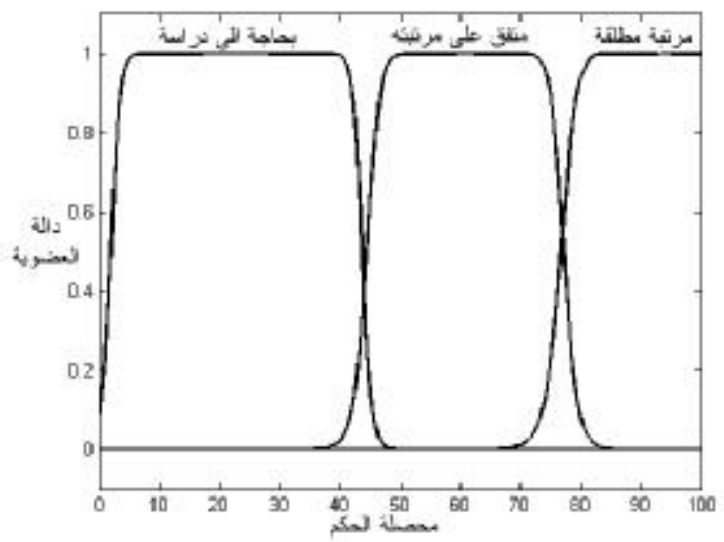

الشكل رقم (6) - دالة العضوية المستخدمة في وصف مستويات محصلة الحكم.

يبدو من الشكل رقم (3) بأن قيمة المتغير الذي يصف دالة عضوية السمات

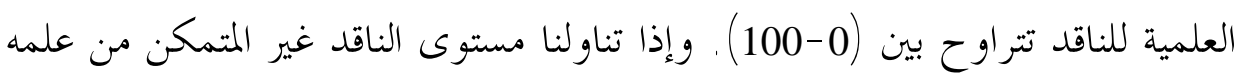
سنجد أن المرتبة التي يستحقها تتراوح بين (0 -20) وأن لكل قيمة مرتبة تحدد مقدار

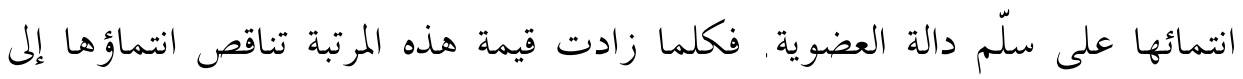

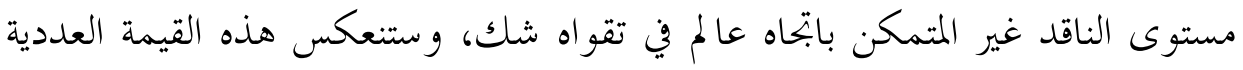
على تحديد قيمة محصلة الحكم في كل حالة من الحالات التي يصدر فيها الناقد حكمه. ويصح الأمر كذلك على بقية المستويات التي تصف هذا فيمة المتغير.

ويصح الأمر على بقية الأشكال (4، 5، 6)؛ حيث بند أنفسنا قبالة مستويات

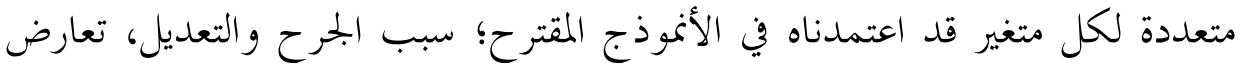

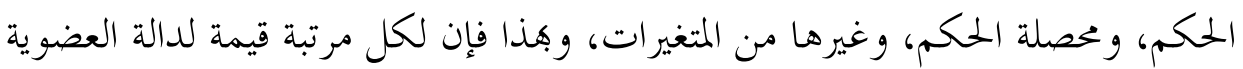

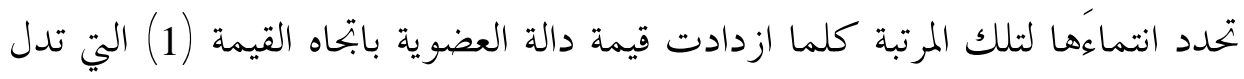

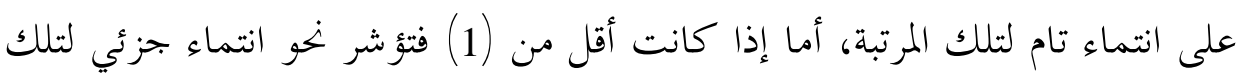
المرتبة.

أما عملية توظيف القواعد المنطقية في بناء الأنموذج فيمكن أن تمنحنا أشكالاً 
ثلاثية الأبعاد تتسم بتعقيد بالغ، ويصعب تفسيرها على العاملين بعلوم الحديث و ونقاد

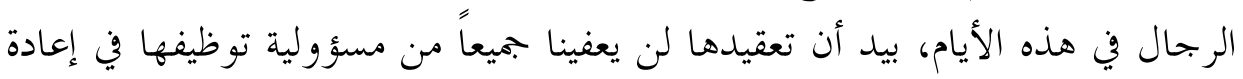

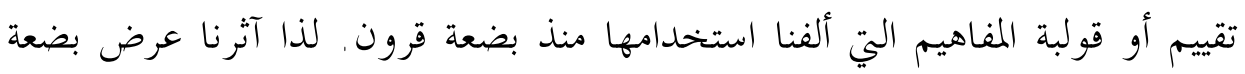

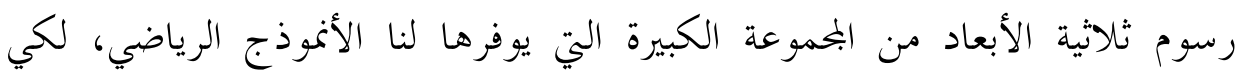
نستقرئ ما تصفه لنا من عملية نقد الرجال، وما الحدود التي يقترحها المنطق الجديد

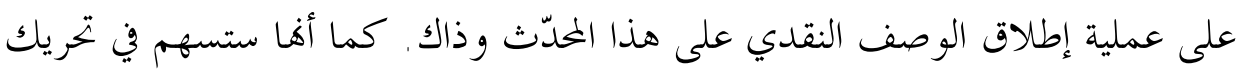
علماء الرجال من سكوفم لكي يوظفوا أدوات المعلوماتية بما يسهم في إثراء الفكر ولئر الإسلامي( أنظر الأشكال 7، 8، 9، 10 على سبيل المثال لا الحصر) .

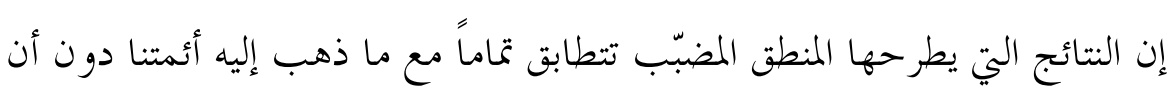
تختلف معهم، بيد أها في الوقت نفسه تسهم في سد بعض الثغرات التي ورثناها نتيجة

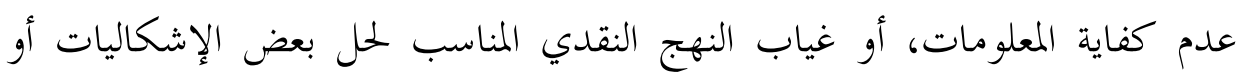
المسائل العويصة.

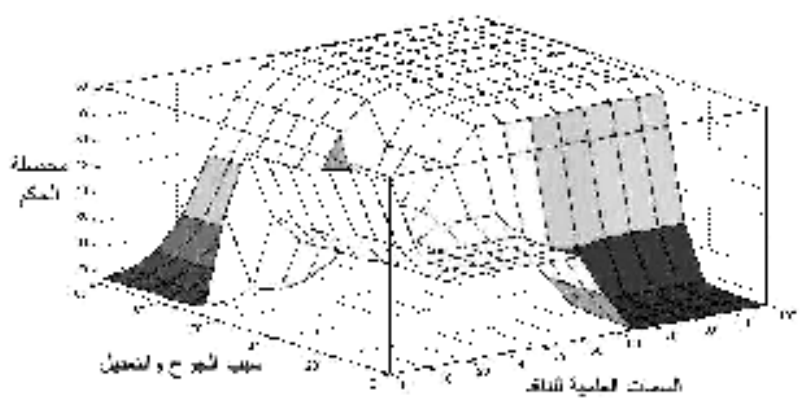

الشكل رقم (7) - التغير في محصلة الحكم في ضوء السمات العلمية للناقد وسبب الجرح و التعديل. 


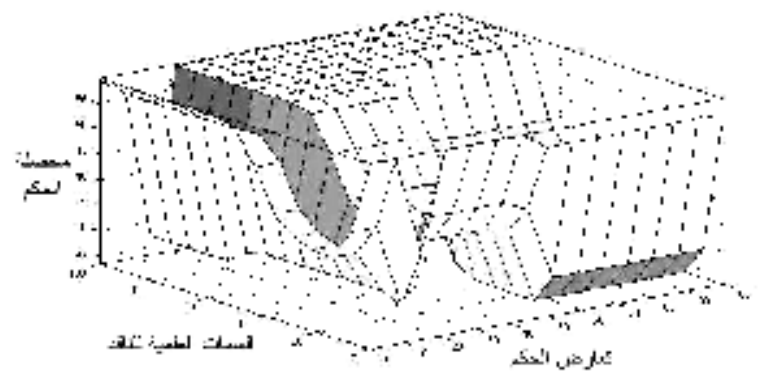

الشكل رقم (8) - التغير في محصلة الحكم في ضوء السمات العلمية للناقد وتعارض الحكم.

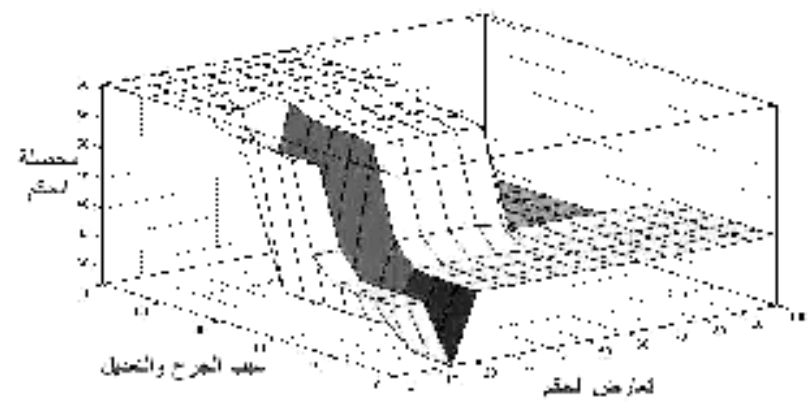

الشكل رقم (9) - التغير في مصلة الحكم في ضوء تعارض الحكم وسبب الجرح و التعديل.

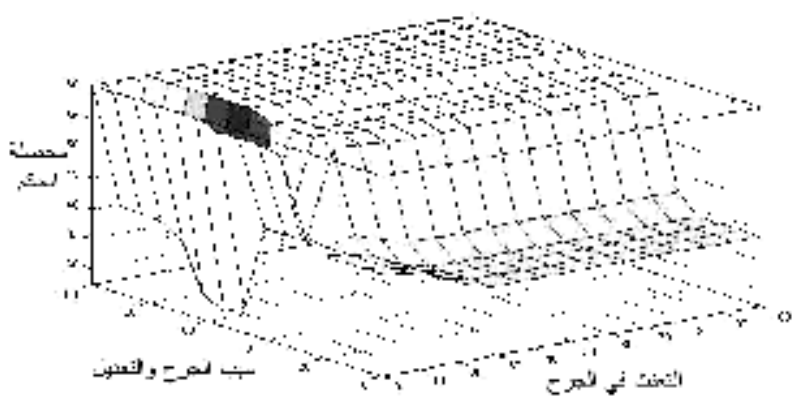

شكل رقم (10) - التغير في معصلة الحكم في ضوء سبب الجرح والتعديل وسمة التعنت في الجرح.

ولكي لا نقحم عالم الحديث، وغير المتخصص بالحوسبة الذكية في نقاشات 
منطقية، وتحليل معلوماتي صوري، سنحاول أن نلفت انتباهه إلى الشكل (10) 28 يبدو

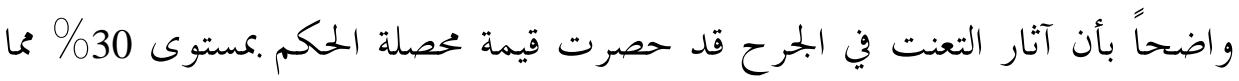
يفقدها أهميتها في حدود غياب سبب الجرح (عندما يكون الجرح مبهماً غير مفسر) .

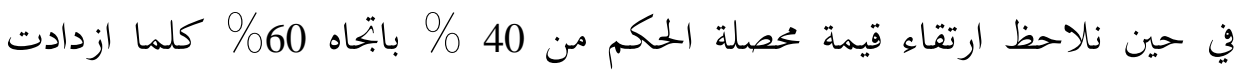

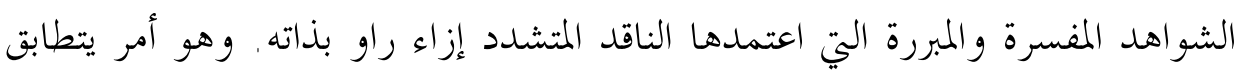
إلى حد كبير مع المنهج النقدي لأئمة الحديث ونقاد الرجال .

كذلك يبدو واضحاً من الأشكال الثلاثية الأبعاد غياب وصف المرتبة المطلقة عن

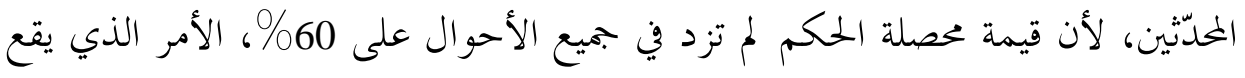
ضمن دالة عضوية المتفق عليه ، انظر الشكل (6) .

وهو أمر يتطابق إلى حد كبير مع أرضية إصدار الحلكم بصدد رجال الحديث،

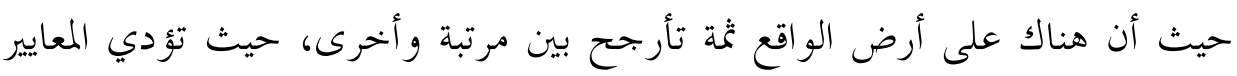

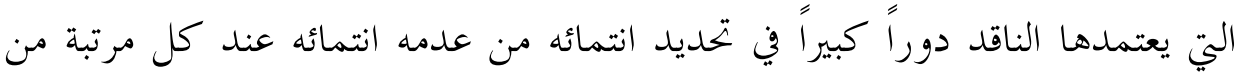
المراتب. فإطلاق أئمة الحديث اصطلاح؛ ثنقة، أو ثبت، أو ضابط، أو متقن، أو حافظ

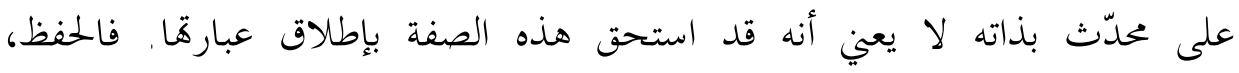

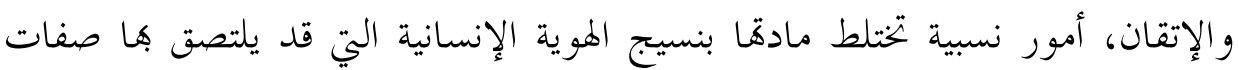

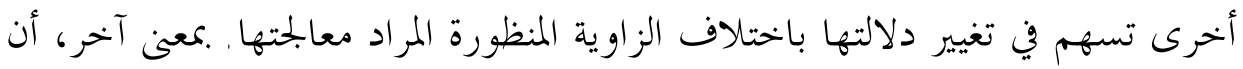
معيار كل صفة من هذه الصفات يتأرجح بين بحموعة من القيم النسبية التي تعد جزءئ من قيمة حقل التغير الواقعة ضمن مستوى صفة الحفظ، أو الإتقان، أو الثقة، وغيرها

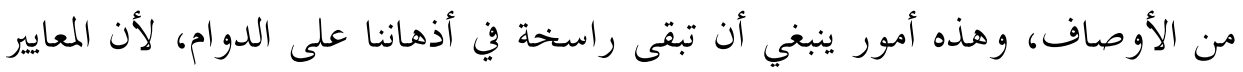
البشرية نسبية، وتفتقر إلى نقطة مرجعية تحدد تخومها بالنسبة لمعيار محدد، أما العلم

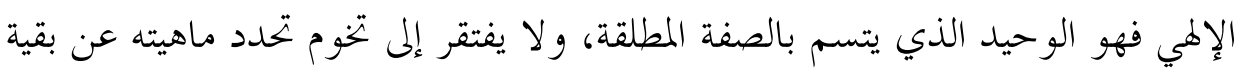
الماهيات التي تشترك معه في البيئة التي يستوطن فيها.

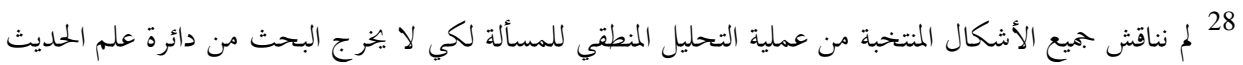

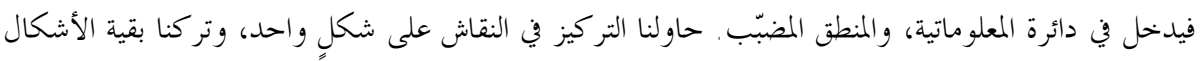
لكي يمعن القارئ نظره في تفاصيلها. 
وإذا حاولنا توظيف أنموذج المنطق المضبّب على بحموعة من نقاد الرجال

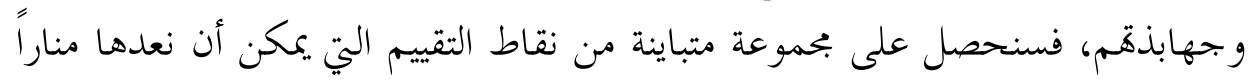

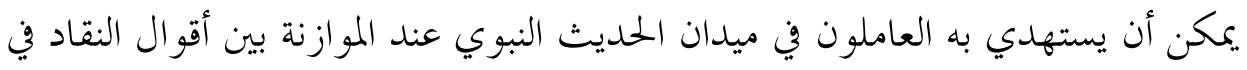

$$
\text { هذا الراوي أو ذاك، انظر الجحدول رقم (3). }
$$

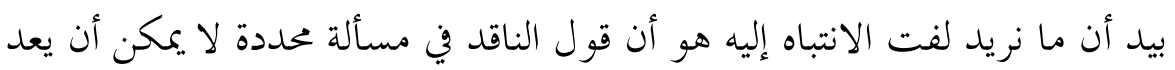

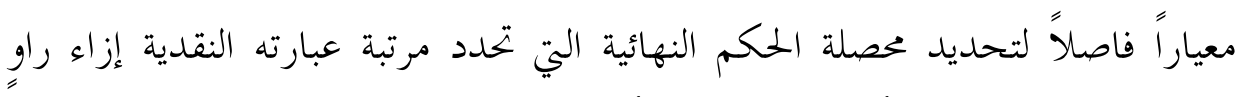

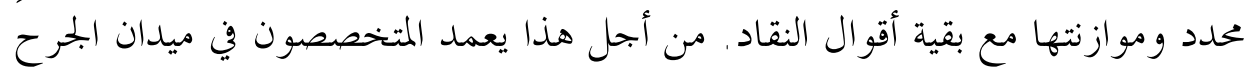

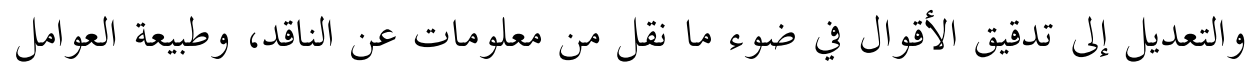

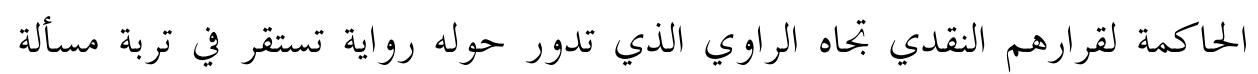

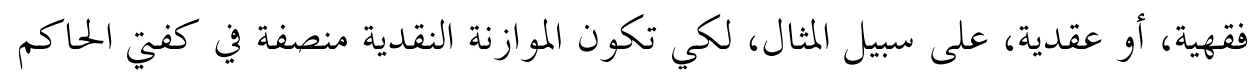
والمكوم عليه.

الجدول رقم (3) - مقارنة بين نتائج الأنموذج المنطقي عن نقاد الرجال.

\begin{tabular}{|c|c|c|c|c|c|c|c|c|}
\hline آلابتداع & الاختلاف & في الجرح & موقف & الأنفاق & تعارض & والتحبرح & العلمية & الناقد \\
\hline$\cdots$ & $\cdots$ & $\cdots$ & متشدد & $\cdots$ & تقديم & $\cdots$ & علمام & "يليى بن \\
\hline$\cdots$ & $\cdots$ & $\cdots$ & متشدد & $\cdots$ & تقديم & $\cdots$ & علمام & مهريد \\
\hline$\cdots$ & $\cdots$ & $\cdots$ & متوسط & $\cdots$ & التفصيل & $\cdots$ & علمه & الترمذي. \\
\hline$\cdots$ & $\cdots$ & $\cdots$ & متوسط & $\cdots$ & التفصيل & $\cdots$ & علمام & أحمد بن \\
\hline$\cdots$ & مذهاف & الكوفينب & متساهل & $\cdots$ & تقلديم & $\cdots$ & تعآلم لديه & الجوزجاني \\
\hline
\end{tabular}


إن الحقول الفارغة تؤشر إلى ضرورة توافر معلومات تفصيلية عن محدّث بذاته

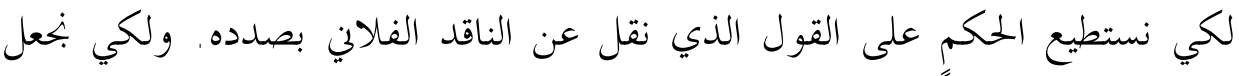

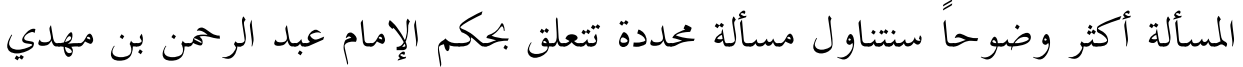

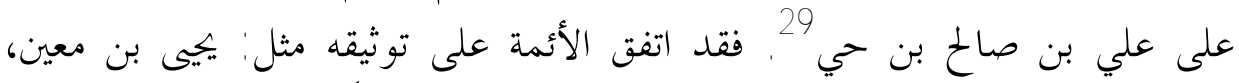

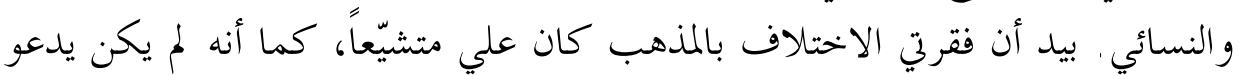

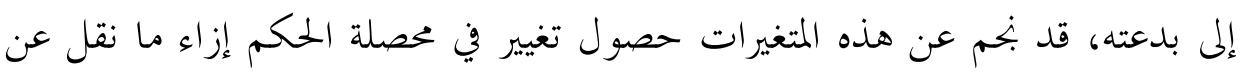

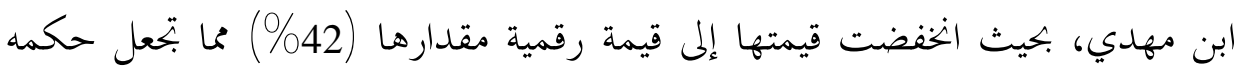

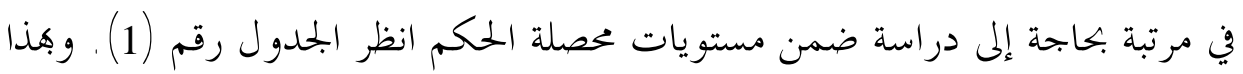

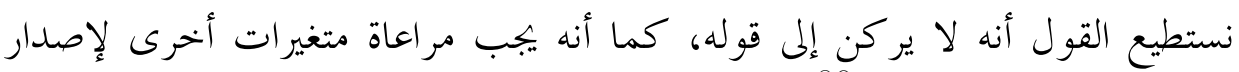

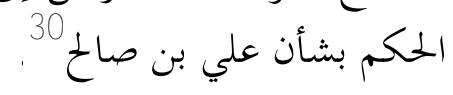

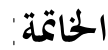

قبل أن نتحدث عن قدرة الأنموذج المقترح في توفير بيانات دقيقة عن المسألة

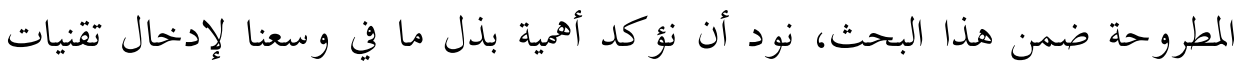

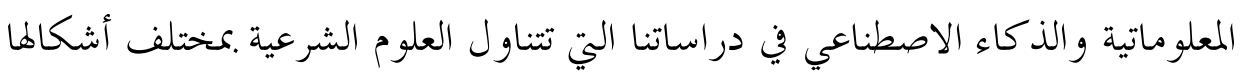

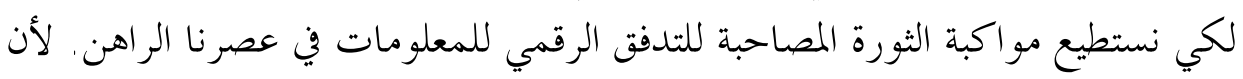

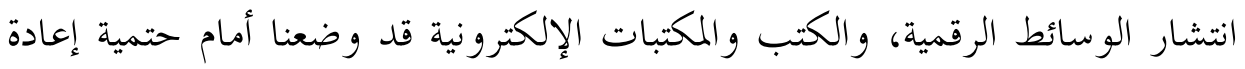

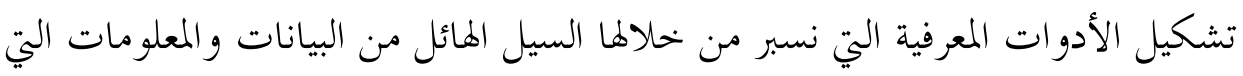
تعجز أدو اتنا التقليدية عن الإحاطة هـا، أو هضم محتو ياهي التها المعرفية.

لقد وجدنا ثمة نقاط كثيرة للالتقاء بين المنطق المضبّب والمنطق الحديثي الذي

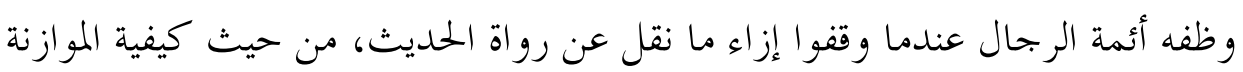

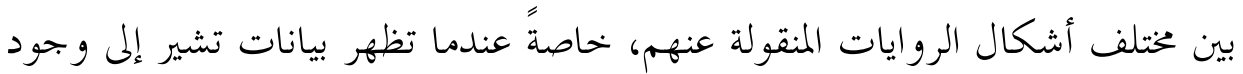

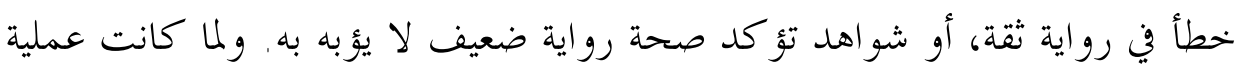

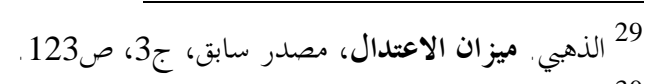

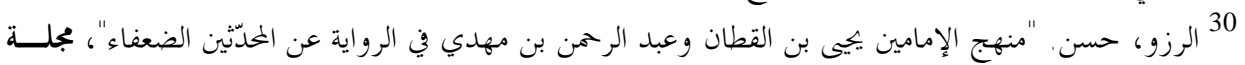

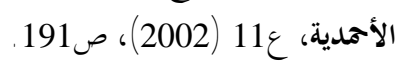


توظيف تقنية المعلومات للمعارف الإسلامية لا تعني إيداع العلوم ومصنفاها في الوسائط

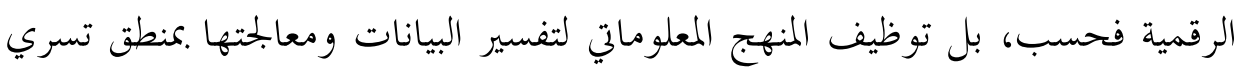

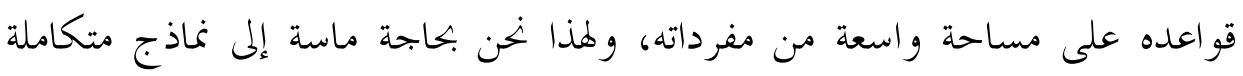

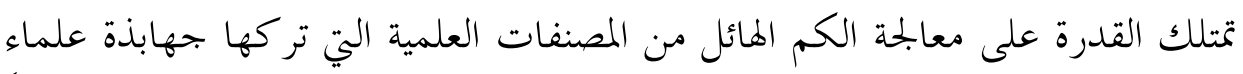

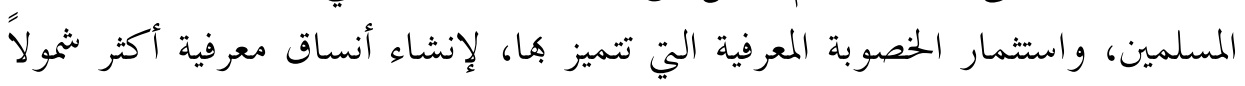
يفتقر إليها الفكر الإسلامي المعاصر.

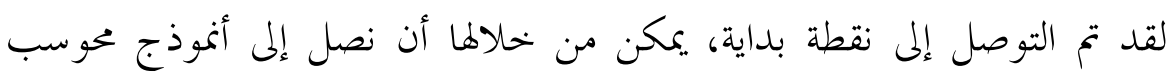

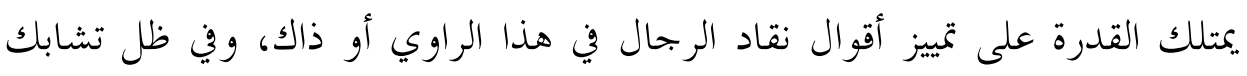

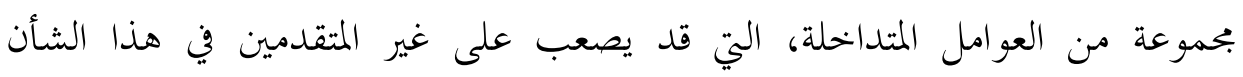

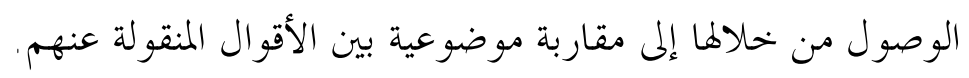

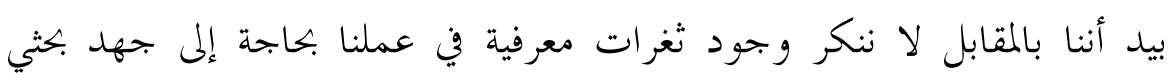

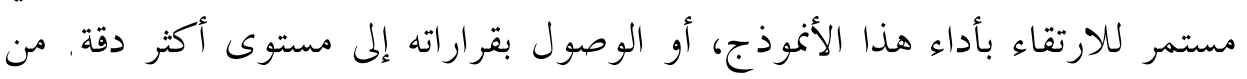

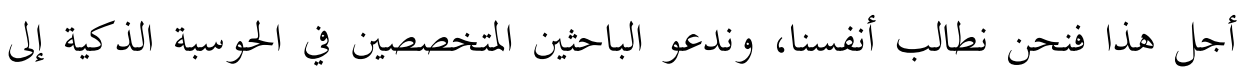

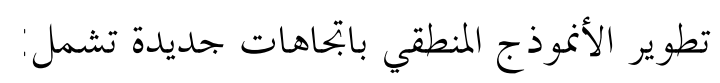

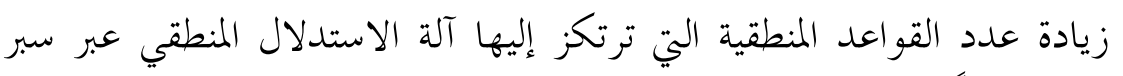

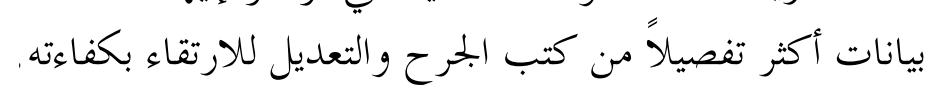

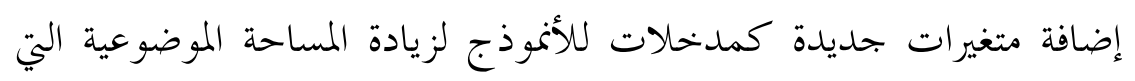
يعالجها.

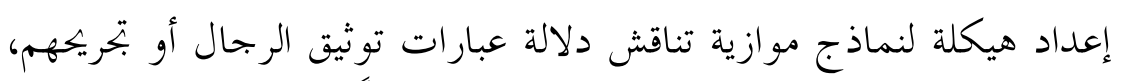

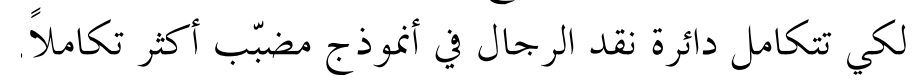

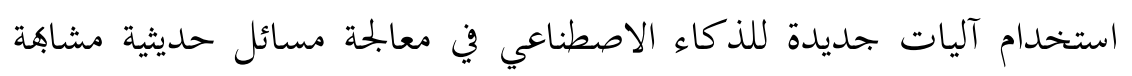

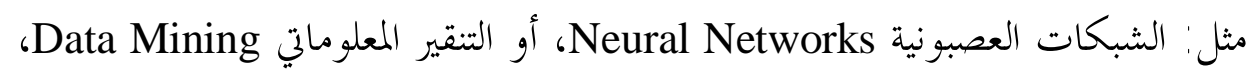

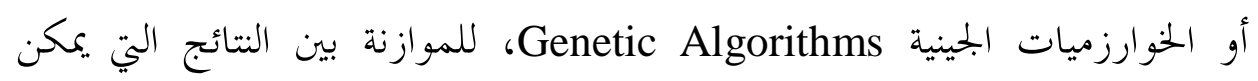

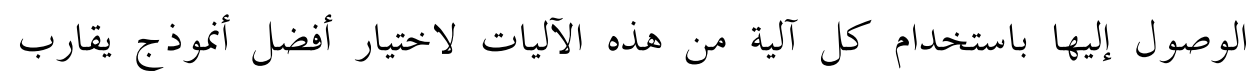
وصف مسائل الجرح و التعديل. 